RoBerto Miquelino de Oliveira BECK

\title{
Comparação entre respostas auditivas de estado estável e avaliação comportamental em crianças candidatas ao implante coclear
}

Tese apresentada à Faculdade de Medicina da Universidade de São Paulo para obtenção do título de Doutor em Ciências

Programa de Otorrinolaringologia

Orientador: Prof. Dr. Rubens de Brito Neto

São Paulo

2015 


\section{Dados Internacionais de Catalogação na Publicação (CIP)}

Preparada pela Biblioteca da

Faculdade de Medicina da Universidade de São Paulo

Creprodução autorizada pelo autor

Beck, Roberto Miquelino de Oliveira

Comparação entre respostas auditivas de estado estável e avaliação

comportamental em crianças candidatas ao implante coclear / Roberto Miquelino de Oliveira Beck. -- São Paulo, 2015.

Tese(doutorado)--Faculdade de Medicina da Universidade de São Paulo. Programa de Otorrinolaringologia.

Orientador: Rubens Vuono de Brito Neto.

Descritores: 1.Implante coclear 2.Potenciais evocados auditivos 3.Perda auditiva 4.Limiar auditivo 5.Audição residual 6.Técnicas de diagnóstico em otologia

USP/FM/DBD-095/15 
DEDICATÓRIA 
À minha mãe, Denise, a quem devo tudo que conquistei e os objetivos a serem alcançados. Exemplo de amor, dedicação, companheirismo, amizade e luta. Nada disso seria possível sem essa lutadora incansável

À minha esposa, Flávia, por seu amor e companheirismo, mesmo nos momentos em que acabei faltando. Você que esteve presente em todas as etapas não poderia faltar nesta.

Aos meus filhos, Luiz Felipe e Giovana, a quem prometo dedicar todo meu amor. Toda a nossa "bagunça" e companhia de vocês esta retratada nesta tese.

Aos meus avós, Roberto e Dionísia, a quem busco retribuir todo o carinho e amor que me dispuseram desde os meus primeiros meses de vida.

À Dra. Signe e Prof. Edigar, meus mentores e inspiradores, sem vocês esse trabalho não seria possível. 
AGRADECIMENTOS 
À Deus, pela saúde, paciência e força para nos guiar todos os dias.

Ao Prof. Dr. Rubens de Brito Neto, Professor associado da Disciplina de Otorrinolaringologia do Hospital das Clínicas da Faculdade de Medicina da USP e orientador desta tese, pelo apoio total durante a elaboração deste projeto.

Ao Prof. Dr. Ricardo Ferreira Bento, Professor Titular Disciplina de Otorrinolaringologia do Hospital das Clínicas da Faculdade de Medicina da USP, por todas as oportunidades a mim concedidas nessa casa. Seu empreendedorismo e visão são exemplo a ser seguido diariamente.

Ao Prof. Luiz Ubirajara Sennes, Professor associado e coordenador do programa de pós-graduação da Disciplina de Otorrinolaringologia do Hospital das Clínicas da Faculdade de Medicina da USP, pelos exemplos de ética e respeito que conduz o Programa.

À Dra. Signe Schuster Grasel, Médica Assistente-Doutora do Hospital das Clínicas da Faculdade de Medicina da Universidade de São Paulo, me acolheu no serviço de Eletrofisiologia como se me conhecesse há anos. Não existem palavras para agradecer todo o aprendizado e amizade ao longo de todos esses anos.

Ao Professor Edigar Resende de Almeida, desde o primeiro momento foi um pai e grande amigo nesta instituição. Todos os dias uma história diferente de onde se extrai muitas risadas e principalmente muito conhecimento.

Ao Dr. Henrique Faria Ramos, Professor Adjunto de Otorrinolaringologia da Universidade Federal do Espírito Santo, companheiro de pesquisa e amigo que conquistei nestes anos de HC. Sempre com uma disposição e qualidade incríveis para colaborar em todas as etapas deste estudo.

Às Fonoaudiólogas do Grupo de Implante Coclear do Hospital das Clínicas da Faculdade de Medicina da USP, pela colaboração na execução dos exames e idéias na elaboração da pesquisa. 
À Profa. Tanit Ganz Sanchez e à Profa. Renata Cantisani di Francesco, pelas orientações no exame de qualificação.

À Dra. Cristina Katayama, Médica-Assistente da Disciplina de Anestesiologia do Hospital das Clínicas da Faculdade de Medicina da USP, por toda a dedicação e carinho com os pacientes e com nossa equipe.

Aos Residentes, Pós-graduandos e Fellows do Departamento de Otorrinolaringologia, em especial, Amanda Rossi, Bernardo Ramos, Jaqueline Quintanilha, Ricardo Loureiro e Samanta Marques, a quem devo o prazer de acordar cedo todos os dias e compartilhar conhecimentos e amizade.

Aos meus sogros João e Thais e meus cunhados Fábio, Fernanda e Carolina, pelo acolhimento e carinho de sempre.

Às secretárias Maria Marileide Alves, Maria Marcia Alves, Lucivânia Lima da Silva e Katia Cota, pela amizade e dedicação diária.

Às Auxiliares de enfermagem Selma Regina Caetano da Silva, Ilza Anardete Rocha e Elisete de Oliveira Brito pelo apoio na realização dos exames e excelente convivência diária.

Aos Pacientes e Familiares, a quem devemos sempre mirar nossos esforços. 
Esta tese está de acordo com as seguintes normas, em vigor no momento desta publicação:

Referências: adaptado de International Committee of Medical Journals Editors (Vancouver).

Universidade de São Paulo. Faculdade de Medicina. Divisão de Biblioteca e Documentação. Guia de apresentação de dissertações, teses e monografias. Elaborado por Anneliese Carneiro da Cunha, Maria Julia de A. L. Freddi, Maria F. Crestana, Marinalva de Souza Aragão, Suely Campos Cardoso, Valéria Vilhena. 3a ed. São Paulo: Divisão de Biblioteca e Documentação; 2011.

As abreviaturas dos títulos dos periódicos estão de acordo com List of Journals Indexed in Index Medicus 
SUMÁRIO 
Lista de Abreviaturas

Lista de Símbolos

Lista de Siglas

Lista de Figuras

Lista de Gráficos

Lista de Tabelas

Resumo

Abstract

1 INTRODUÇÃO .1

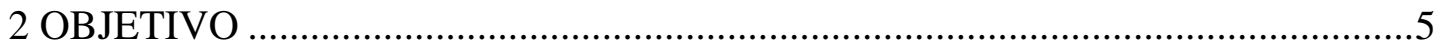

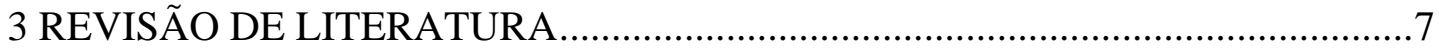

3.1 Perda auditiva, implante coclear e audição residual .....................................8

3.2 Respostas auditivas de estado estável ..........................................................11

3.3 Avaliação de audição residual através das respostas auditivas de estado

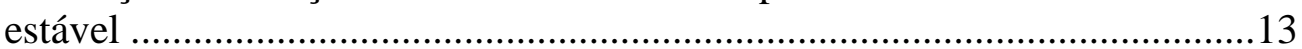

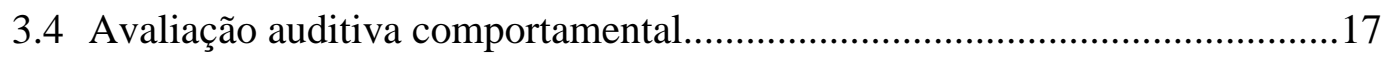

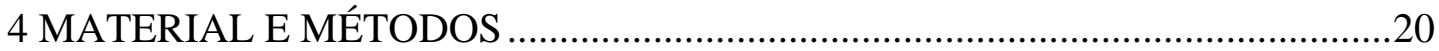

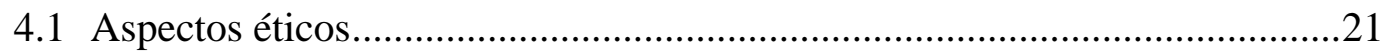

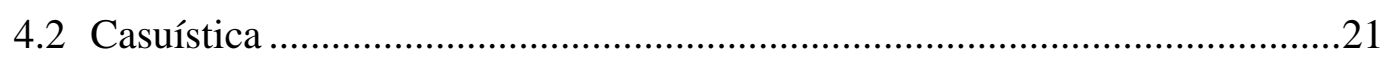

4.2.1 Critérios de inclusão .........................................................................21

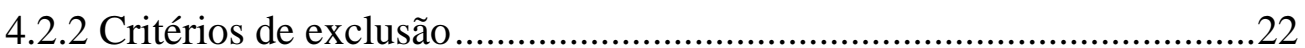

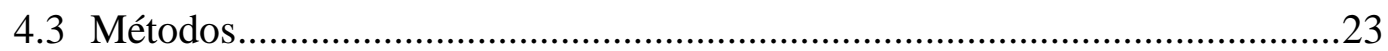

4.3.1 Respostas auditivas de estado estável .............................................23

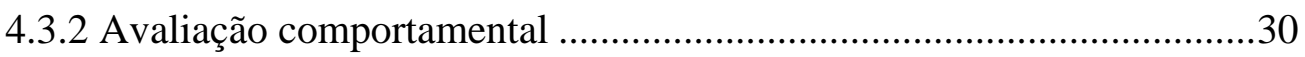

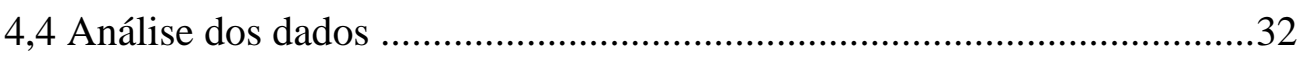

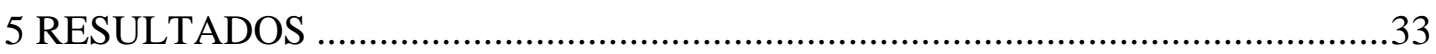

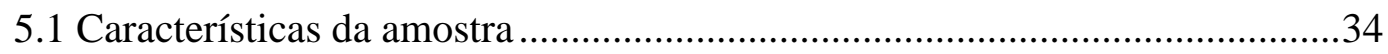

5.2 Respostas obtidas na audiometria com reforço visual....................................35

5.3 Respostas obtidas nas respostas auditivas de estado estável...........................36

5.4 Comparação entre limiares à RAEE e na avaliação por VRA .........................37

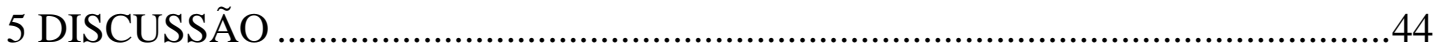

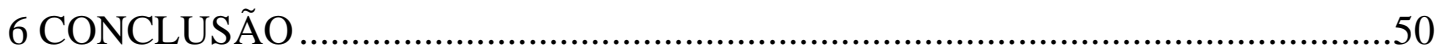

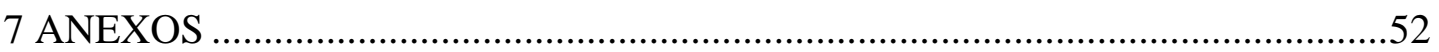

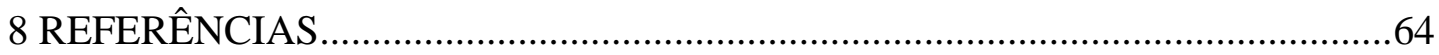


LISTAS 


\section{ABREVIATURAS}

\begin{tabular}{ll} 
AM & Amplitude Modulation \\
DP & desvio-padrão \\
EEG & Eletroencefalograma \\
EOAPD & Emissões otoacústicas por produtos de distorção \\
ed. & Edição \\
et al. & e outros \\
FFT & Fourier Fast Transformation \\
FM & Frequency Modulation \\
IT-MAIS & Infant-toddler Meaningful Auditory Integration Scale \\
MASTER & Multiple Auditory Steady-State Responses \\
MRL & Minimum Response level (nível mínimo de resposta) \\
N & número \\
p. & página \\
p. ex. & por exemplo \\
PEATE & Potencial Evocado Auditivo de Tronco Encefálico \\
RAEE & Respostas Auditivas de Estado Estável \\
RITLS & Rhode Island Test of Language Structure \\
VRA & Visual Reinforcement Audiometry \\
\hline
\end{tabular}




\section{SÍMBOLOS}

$\begin{array}{ll}\mathrm{dB} & \text { decibél } \\ \mathrm{dB} \text { NA } & \text { decibél nível de audição } \\ \mathrm{Hz} & \text { Hertz } \\ \mathrm{KHz} & \text { Quilohertz } \\ \mathrm{KOhm} & \text { Quilo-ohm } \\ \mathrm{mm} & \text { milímetro } \\ \mathrm{ms} & \text { milissegundo } \\ \mathrm{nV} & \text { nanovolt } \\ \mathrm{s} & \text { segundo } \\ \mathrm{V} & \text { volt } \\ \mathrm{W} & \text { watt } \\ \mu \mathrm{V} & \text { microvolt } \\ < & \text { menor que } \\ > & \text { maior que } \\ \geq & \text { igual ou maior }\end{array}$


SIGLAS

ABORL-CCF

Associação Brasileira de Otorrinolaringologia e Cirurgia

Cérvico-Facial

CAPPesq

Comissão de Ética para Análise de Projetos de Pesquisa

FDA

Food and Drug Administration

HCFMUSP

Hospital das Clínicas da Faculdade de Medicina da

Universidade de São Paulo

SUS

Sistema Único de Saúde 
FIGURAS

Figura 1 - Organograma para aplicação dos critérios de exclusão …..................22

Figura 2 - Tom contínuo sinusoidal para frequência portadora de $500 \mathrm{~Hz}$........24

Figura 3 - Tom contínuo sinusoidal para frequência portadora de $1000 \mathrm{~Hz}$......25

Figura 4 - Tom contínuo sinusoidal para frequência portadora de $2000 \mathrm{~Hz}$......25

Figura 5 - $\quad$ Tom contínuo sinusoidal para frequência portadora de $4000 \mathrm{~Hz} \quad$......25

Figura 6 - Seleção de estímulos e parâmetros no "software" Multiple Auditory Steady-State Responses ................................................27

Figura 7 - Registro das RAEE no "software" 2.04.i.00 do Sistema BioLogic Navigator Pro na frequência portadora de $500 \mathrm{~Hz}$.................28

Figura 8 - Audiograma eletrofisiológico com as respostas obtidas nas frequências em ambas as orelhas ...................................................22

Figura 9 - Modelo esquemático da montagem da sala para avaliação

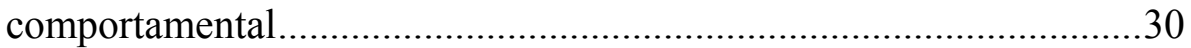




\section{GRÁFICOS}

Gráfico 1 - Distribuição dos limiares e respostas ausentes à avaliação comportamental (VRA) nas frequências de 500, 1000, 2000 e $4000 \mathrm{~Hz}$

Gráfico 2 - Distribuição dos limiares e respostas ausentes à RAEE, nas frequências de 500, 1000, 2000 e $4000 \mathrm{~Hz}$.

Gráfico 3 - Respostas por categoria em cada método na frequência de $500 \mathrm{~Hz}$. Foram divididas se resposta ausente, limiar entre $90 \mathrm{e}$ $110 \mathrm{~dB}$ ou $<90 \mathrm{~dB}$

Gráfico 4 - Respostas por categoria em cada método na frequência de $1000 \mathrm{~Hz}$. Foram divididas se resposta ausente, limiar entre $90 \mathrm{e}$ $110 \mathrm{~dB}$ ou $<90 \mathrm{~dB}$

Gráfico 5 - Respostas por categoria em cada método na frequência de $2000 \mathrm{~Hz}$. Foram divididas se resposta ausente, limiar entre $90 \mathrm{e}$ $110 \mathrm{~dB}$ ou $<90 \mathrm{~dB}$

Gráfico 6 - Respostas por categoria em cada método na frequência de $4000 \mathrm{~Hz}$. Foram divididas se resposta ausente, limiar entre $90 \mathrm{e}$ $110 \mathrm{~dB}$ ou $<90 \mathrm{~dB}$ 
TABELAS

Tabela 1 - Média, desvio-padrão e diferença das médias nas frequências de 500, 1000, 2000 e $4000 \mathrm{~Hz}$, na comparação entre VRA e RAEE

Tabela 2 - Comparação entre VRA e RAEE. Divisão dos limiares obtidos em faixa de intensidades de acordo com o grau de perda. Utilizado teste Kappa ponderado para estatística. Nas colunas da direita, observa-se medidas de sensibilidade e especificidade para cada umas das 4 frequências testadas. 
RESUMO 
Beck RMO. Comparação entre respostas auditivas de estado estável e avaliação comportamental em crianças candidatas ao implante coclear [Tese]. São Paulo: Faculdade de Medicina, Universidade de São Paulo; 2015.

INTRODUÇÃO: As Respostas Auditivas de Estado Estável permitem avaliação frequência específica em intensidades de até $120 \mathrm{~dB}$ NA e a detecção de audição residual em pacientes com perda auditiva severo-profunda. O objetivo deste estudo é comparar os limiares à RAEE e os resultados da avaliação comportamental em crianças com suspeita de surdez severo-profunda. MÉTODO: Estudo transversal para comparar respostas à RAEE e por audiometria com reforço visual (VRA) em 63 crianças candidatas ao implante coclear (126 orelhas) com idade entre 6 e 72 meses. Foram incluídas crianças com otomicroscopia normal, ausência de respostas ao PEATE clique a $90 \mathrm{~dB}$ NA e às emissões otoacústicas. Foram excluídas crianças com malformações de orelha interna, doenças do espectro da neuropatia auditiva, ou que não completaram a avaliação comportamental ou não atingiram ruído eletroencefalográfico $<30 \mathrm{nV}$ durante a RAEE. Foram utilizados estímulos com tons contínuos sinusoidais (100\% AM e 20\% FM) nas frequências de 500, 1000, 2000 e $4000 \mathrm{~Hz}$ em intensidade máxima de $110 \mathrm{~dB}$ NA. Os limiares à VRA foram obtidos por tom warble nas frequências de 500,1000, 2000 e $4000 \mathrm{~Hz}$ em cada orelha através de fones de inserção (ER-5A) ou tipo casco (TDH-39). A intensidade máxima de estimulação foi de $120 \mathrm{~dB}$ NA em cada frequência. RESULTADOS: Limiares comportamentais foram obtidos em 36,7\% (185/504) de todas as frequências em todas as crianças, $9 \%$ em intensidade maior que $110 \mathrm{~dB}$ NA. Entre as 504 medidas da RAEE em 63 indivíduos, 53 limiares foram obtidos (10,5\%). Ao todo, 89,5\% das frequências testadas não apresentaram nenhuma resposta em $110 \mathrm{~dB}$ NA. A distribuição dos limiares à RAEE foi semelhante à da avaliação comportamental. A maioria das respostas foram em $500 \mathrm{~Hz}$, diminuindo nas frequências agudas. A diferença média entre os limiares à VRA e à RAEE variou entre 0,09 e 8,94 dB. Foram realizadas 27 comparações entre RAEE e VRA: 12 em 500 Hz, 9 em 1000 $\mathrm{Hz}, 5 \mathrm{em} 2000 \mathrm{~Hz}$ e $1 \mathrm{em} 4000 \mathrm{~Hz}$. Respostas ausentes foram observadas em ambos os testes em 38,1\% em $0,5 \mathrm{KHz}, 52,45 \%$ em $1 \mathrm{KHz}, 74,6 \%$ em $2 \mathrm{KHz}$ e $81,0 \%$ em 4 KHZ. A especificidade foi $>90 \%$ em 1, 2 e $4 \mathrm{KHz}$. Nas orelhas sem resposta comportamental em $120 \mathrm{~dB}$ NA, todos os limiares à RAEE estavam na faixa de perda profunda, $90 \%$ deles $\geq 110 \mathrm{~dB}$ NA. CONCLUSÃO: A ausência de respostas nas altas intensidades na RAEE foi o principal achado (especificidade $>90 \%$ ) o que prediz limiares comportamentais na faixa de surdez profunda.

Descritores: implante coclear; potenciais evocados auditivos; perda auditiva; limiar auditivo; audição residual; técnicas de diagnóstico em otologia. 
ABSTRACT 
Beck RMO. Comparison between Auditory Steady-State Responses and behavioral audiometry in pediatric cochlear implant candidates [Thesis]. São Paulo: "Faculdade de Medicina, Universidade de São Paulo"; 2015.

Introduction and Objective: ASSR allows frequency-specific evaluation in intensities up to $120 \mathrm{~dB}$ HL and detection of residual hearing in patients with severe-toprofound hearing loss. The aim of this study was to compare ASSR thresholds and behavioral test results in children with suspected severe-to-profound hearing loss. Methods: A cross sectional study was carried out to compare ASSR and Visual Reinforcement Audiometry (VRA) responses in 63 pediatric cochlear implant candidates (126 ears) aged between 6 to 72 months. We included children with normal otomicroscopy findings, absent responses to click-ABR at $90 \mathrm{~dB} \mathrm{HL}$ and otoaccoustic emissions. We excluded children with inner ear malformations, auditory neuropathy spectrum disorder or who did not complete VRA or achieve EEG noise $<$ $30 \mathrm{nV}$ during the ASSR test. Air-conduction ASSR stimuli were continuous sinusoidal tones $(100 \% \mathrm{AM}$ and $20 \% \mathrm{FM})$ presented at $0.5,1,2$ and $4 \mathrm{kHz}$ starting at the maximum presentation level of $110 \mathrm{~dB}$ HL. VRA thresholds were acquired with warble tones presented at $0.5,1,2$ and $4 \mathrm{KHz}$ in each ear through ER-tone $5 \mathrm{~A}$ or TDH-39 phones. Maximum presentation level was $120 \mathrm{~dB}$ HL for each frequency. Results: Behavioral thresholds were obtained in 36.7\% (185/504) of all frequencies in all subjects, $9 \%$ were in intensities $>110 \mathrm{~dB}$ HL. Among 504 ASSR measurements from 63 subjects, 53 thresholds were obtained (10.5\%). Overall 89.5\% of the tested frequencies did not show any response at $110 \mathrm{~dB}$ HL. The distribution of ASSR responses was similar to the behavioral test results. Most responses were at $500 \mathrm{~Hz}$, decreasing among the higher frequencies. Mean differences between behavioral and ASSR thresholds varied from 0.09 to $8.94 \mathrm{~dB}$. Overall, 27 comparisons of behavioral and ASSR thresholds were obtained: 12 at $0.5 \mathrm{KHz}, 9$ at 1 $\mathrm{KHz}, 5$ at $2 \mathrm{KHz}$ and 1 at $4 \mathrm{KHz}$. Absent responses were observed in both tests in $38.1 \%$ at $0.5 \mathrm{KHz}, 52.4 \%$ at $1 \mathrm{KHz}, 74.6 \%$ at $2 \mathrm{KHz}$ and $81.0 \%$ at $4 \mathrm{KHz}$. The specificity was $>90 \%$ at 1,2 and $4 \mathrm{KHz}$. In ears with no behavioral response at 120 $\mathrm{dB}$ HL all ASSR thresholds were in the profound hearing loss range, $90 \%$ of them were equal or $>$ than $110 \mathrm{~dB}$ HL. Conclusion: Among 63 pediatric CI candidates, absent responses to high-intensity ASSR was the major finding (specificity $>90 \%$ ) predicting behavioral thresholds in the profound hearing loss range. These findings can be helpful to confirm the decision for cochlear implantation.

Descriptors: Cochlear implantation; evoked potentials, auditory; hearing loss; auditory thresholds; residual hearing; diagnostic techniques, otological. 
INTRODUÇÃO 


\section{INTRODUÇÃO}

Com a implementação e ampla propagação da triagem auditiva neonatal universal, um maior número de recém-nascidos é identificado com perda auditiva e, consequentemente, necessitará de uma avaliação audiológica completa para possível reabilitação auditiva. Enquanto crianças com perda auditiva moderada podem se beneficiar do uso de próteses auditivas, aquelas identificadas com perdas severas e/ou profundas são candidatas em potencial ao implante coclear.

Diversos fatores contribuem para o sucesso do implante coclear em relação à percepção da fala e desenvolvimento da linguagem, como por exemplo, idade de indicação e cirurgia do implante ${ }^{[1,2]}$, tempo de privação sensorial e audição residual $[3,4]$.

Em adultos, a demonstração de que pacientes com audição residual apresentam melhor ganho com implante coclear multicanal do que com a

protetização ${ }^{[5,6]}$, estendeu os critérios de seleção para indivíduos com perda auditiva neurossensorial severa (média dos limiares tonais de 71 a 90 dB NA) com reconhecimento de sentenças em formato aberto menor ou igual a $30 \%{ }^{[7]}$.

De acordo com a Associação Brasileira de Otorrinolaringologia e Cirurgia Cérvico-Facial (ABORL-CCF), 2011 nas crianças até 6 anos de idade, as indicações de implante coclear são: - perda auditiva neurossensorial bilateral severa/profunda; experiência com uso de prótese auditiva por um período mínimo de 3 meses na perda auditiva severa; - motivação adequada da família para o uso e processo de reabilitação fonoaudiológica ${ }^{[8,9]}$.

A avaliação audiológica comportamental, é realizada em crianças e se baseia na observação das respostas comportamentais evidenciadas por estímulos acústicos instrumentais (instrumentos musicais de percussão), tons puros (audiômetro pediátrico) e sons verbais. As respostas esperadas são: reflexo cócleo-palpebral, procura da fonte sonora, cessação da atividade corporal, mudança na expressão facial e visual, choro, risos, entre outros. Os estímulos são apresentados em ordem decrescente de intensidade, sendo que os bebês de até três meses de vida devem estar em estado de sonolência e após essa faixa etária, em estado de alerta. 
À partir dos cinco ou seis meses de vida ${ }^{[10,11]}$, a avaliação audiológica pode ser feita através do audiômetro pediátrico, que possibilita noção aproximada do grau de perda auditiva. Este tipo de avaliação tem característica mais qualitativa que quantitativa. As vantagens são baixo custo e disponibilidade da aparelhagem em grande parte dos serviços. A principal desvantagem é a suscetibilidade a interferências ambientais, como ruídos, pistas visuais e interferência dos pais ${ }^{[12]}$, além da necessidade de dois ou mais examinadores.

Com a diminuição da idade de diagnóstico e a ampliação da indicação de implante coclear, os exames eletrofisiológicos são cada vez mais importantes, uma vez que a avaliação comportamental nem sempre é possível de ser completada em crianças pequenas e muitas vezes não são avaliadas as orelhas separadamente ${ }^{[13,14]}$. Os exames eletrofisiológicos mais utilizados, até o presente, para se estimar o limiar eletrofisiológico são o potencial evocado auditivo de tronco encefálico (PEATE) com clique e tone burst. Devido à natureza transiente do estímulo usado para os potenciais evocados, a intensidade máxima de estimulação é de $95 \mathrm{~dB}$ nível de audição (NA). Sob este aspecto, a possibilidade de audição residual não pode ser investigada com o PEATE ${ }^{[15]}$. A ausência de respostas ao PEATE sugere a presença de surdez severa-profunda, mas não diferencia entre surdez severa e profunda.

O exame de Respostas Auditivas de Estado Estável (RAEE) é uma ferramenta utilizada para a avaliação objetiva da audição. As RAEE são evocadas por tons contínuos modulados frequência-específicos que possibilitam níveis mais elevados de estimulação ${ }^{[16]}$. As RAEE podem fornecer informações de limiar em intensidades elevadas de até $120 \mathrm{~dB}$ ou mais ${ }^{[15,16]}$, permitindo uma avaliação mais fidedigna de resíduos auditivos. Por essas razões, as RAEE são uma ferramenta importante para avaliação auditiva em crianças candidatas ao implante coclear, proporcionando ainda mais segurança na adaptação e programação da prótese auditiva, como procedimento desejável pré-implante coclear.

Em crianças pequenas, a avaliação comportamental pode ser de difícil execução e depende das condições neuropsicológicas para colaboração. Com isso, muitas vezes o resultado não reflete os limiares auditivos. 
Desta forma, a avaliação objetiva é de extrema importância na decisão da conduta, assim como na escolha da orelha a ser implantada, se a opção for por implante unilateral, conforme preconizado pelo Sistema Único de Saúde (SUS) ${ }^{[17]}$. A importância da avaliação comportamental é muito grande, mas para maiores esclarecimentos é indispensável nos dias atuais, uma avaliação objetiva confiável para a indicação de implante coclear ou protetização eficiente.

Em razão da possibilidade de preservação de resíduos auditivos na cirurgia de implante coclear ${ }^{[18-20]}$, redução da idade mínima para cirurgia do implante coclear e aumento das indicações de implantes bilaterais, a importância da detecção da audição residual torna-se cada vez maior, pois sua presença está relacionada à uma via neural ativa e o menor tempo de privação sensorial melhora o prognóstico do implante ${ }^{[21-}$ 23].

Desde 1998, poucos estudos foram realizados com o intuito de investigar a RAEE em crianças portadoras de surdez severo-profunda. Cada vez mais se indica o exame de RAEE para os candidatos a implante pela possibilidade da estimulação em altas intensidades ( $>95 \mathrm{~dB}$ NA). Existe a necessidade evidente de se proceder estudo comparando a RAEE e a avaliação comportamental. 
OBJETIVO 
Objetivo 6

\section{OBJETIVO}

O objetivo do estudo é comparar os limiares obtidos pelas respostas auditivas de estado estável com os limiares tonais obtidos na avaliação comportamental nas frequências de 500, 1000, 2000 e $4000 \mathrm{~Hz}$, em crianças candidatas ao implante coclear. 


\section{REVISÃO DE LITERATURA}




\subsection{PERDA AUDITIVA, IMPLANTE COCLEAR E AUDIÇÃO RESIDUAL}

A indicação de implante coclear foi inicialmente restrita a pacientes com perda auditiva neurossensorial profunda. Com o desenvolvimento dos implantes cocleares multicanais e o aperfeiçoamento da tecnologia de processamento sonoro, o desempenho e eficácia dos implantes melhoraram, aumentando o desempenho da percepção da fala ${ }^{[24,25]}$.

As melhorias do processamento da fala e percepção de sentenças em formato aberto, trouxe aos usuários de implante coclear, com perda auditiva profunda, desempenho auditivo igual ou melhor quando comparados àqueles com uso de prótese auditiva e perda auditiva severa ${ }^{[26]}$.

Com a mudança dos critérios de indicação de implante coclear à partir de meados da década de 90, foram incluídos pacientes portadores de perda auditiva severa ${ }^{[7]}$ com ganho limitado com prótese auditiva, ou seja, perda auditiva de grau severo associada a discriminação inferior a 30\% para sentenças em formato aberto. Esta expansão dos critérios orientou as pesquisas em torno dos benefícios do implante em relação às próteses.

Yoshinaga-Itano et al. em $1998^{[27]}$ demonstraram que crianças diagnosticadas com perda auditiva e submetidas precocemente à intervenção (antes do primeiro ano de vida) tem resultados melhores na linguagem, vocabulário, inteligibilidade da fala e repertório de fonemas.

Van den Borne et al. (1998) ${ }^{[28]}$, compararam crianças com prótese auditiva e implante coclear após 24 meses de uso e verificaram diferença estatisticamente significativa no escore de detecção sonora (1,9 e 3,5 pontos, respectivamente), mas não analisaram a percepção de fala.

Tomblin et al. (1999) ${ }^{[29]}$, com a aplicação de testes de reconhecimento de fala em língua inglesa (RITLS e YPSyn), demonstraram que as crianças usuárias de 
implante coclear, após dois anos de experiência, conseguiam melhor produção e compreensão da linguagem em comparação aos usuários de prótese auditiva.

Crianças usuárias de implante coclear com melhores limiares pré-operatórios de audição residual obtiveram melhores resultados na percepção de monossílabos, dissílabos e trissílabos ${ }^{[30]}$, além de palavras e sentenças com formato aberto ${ }^{[3,4,30-33]}$ quando comparadas à crianças que não demonstraram respostas, que não foram estimuladas previamente ou que não usaram próteses auditivas. Kiefer et al., 1998 atribuíram o achado a experiência auditiva prévia e à maturação das vias auditivas centrais ${ }^{[30]}$.

Apesar de amplamente estudada e aplicada, a definição de audição residual é bastante variável na literatura. Fraysse et al. (1998) ${ }^{[34]}$ definiram audição residual como os limiares mensuráveis até os limites do audiômetro, nas frequências entre 500 e 8000 Hz. Já Kiefer et al. (1998) ${ }^{[30]}$ definiram como presença de resposta em intensidade menor ou igual a $110 \mathrm{~dB}$ NA, em pelo menos duas frequências entre 250 e $4000 \mathrm{~Hz}$. Shiomi et al. (1999) ${ }^{[35]}$ optaram pela média dos limiares tonais de 500, 1000 e $2000 \mathrm{~Hz}$ entre 70 e 110 dB NA. Soda-Merhy et al. (2008) ${ }^{[36]}$ definiram resíduos auditivos como presença de audição perceptível em pelo menos três frequências.

Francis et al. (2004) ${ }^{[37]}$, avaliaram 3 grupos de adultos: perda severa bilateral $(n=20)$, perda severa em uma orelha e profunda na contralateral $(n=23)$ e surdez profunda bilateral $(n=43)$. Observaram que a presença de audição residual estaria relacionada a melhor percepção da fala após implante coclear nos grupos com perda severa, já que está relacionada à habilidade das vias auditivas centrais em decodificar as informações da fala. O pior desempenho foi entre aqueles com perda profunda bilateral.

Baudonck et al. (2010) ${ }^{[38]}$, estudaram crianças entre 6 e 15 anos de idade. Foram avaliados 3 grupos: perda auditiva profunda (implantados), normouvintes e perda auditiva de moderada a severa (em uso de prótese auditiva). Mostraram que os usuários de implante coclear apresentavam inteligibilidade de fala semelhante a normouvintes, com discriminação entre 96\% e 100\%, respectivamente, e crianças com prótese auditiva apresentaram discriminação média de $92 \%$. 
A indicação de implante coclear nas crianças está relacionada ao aproveitamento da prótese auditiva. Russell et al. (2013) ${ }^{[39]}$ consideraram que aquelas crianças com bom aproveitamento não deveriam ser implantadas. Descreveram 3 fatores para justificar este fato como o dano irreversível à orelha interna, o período de tempo entre a cirurgia e os benefícios efetivos e a dificuldade de se testar a prótese em crianças pequenas.

O período entre 6 meses e 3 anos é crucial no desenvolvimento auditivo e da linguagem e justamente nesta fase a decisão de implantar-se ou não é mais difícil. As diretrizes do US Food and Drug Administration (FDA) ${ }^{[40]}$ sobre os candidatos ao implante coclear especificaram que menores de 2 anos deveriam ter surdez profunda bilateral e os maiores de 2 anos perda auditiva severa-profunda. Em ambas as categorias, as crianças deveriam fazer teste com prótese auditiva por 3 a 6 meses e demonstrar resultados desfavoráveis ${ }^{[41]}$.

Govaerts et al. (2002) ${ }^{[42]}$, Tajudeen et al. (2010) ${ }^{[43]}$ e Colletti et al. (2012) ${ }^{[44]}$ mostraram que crianças implantadas antes dos dois anos tem melhor audição e percepção de linguagem, se comparados aos implantados mais tardiamente. Tal observação vai de encontro aos achados de Sharma et al. (2011) ${ }^{[45]}$ que consideraram que o implante deve ser realizado até os dois anos de vida para que se aproveite o período de maior neuroplasticidade da via auditiva e córtex cerebral, o que ofereceria à criança maior possibilidade de desenvolvimento da audição e linguagem. Ainda, Tobey et al. (2011) ${ }^{[46]}$ mostraram que crianças implantadas precocemente tem maior facilidade em ser compreendidas por outras pessoas.

Nas crianças, os testes habituais de reconhecimento de palavras e sentenças, tanto no pré quanto no pós-operatório, são difíceis de serem aplicados. Por isso, naquelas que ainda não tem linguagem, testes de observação do comportamento são realizados e quantificados. Um dos mais utilizados é o IT-MAIS (Infant-toddler Meaningful Auditory Integration Scale) que através de entrevista com os pais avaliam respostas ao chamado do nome e sons ambientais ${ }^{[47]}$.

Em crianças maiores, a habilidade em se usar o telefone é um bom indicador de sucesso, já que não existem as pistas visuais. Uziel et al. (2007) ${ }^{[48]}$ mostraram que 
$79 \%$ das crianças com mais de 10 anos de implante coclear conseguiam falar ao telefone com familiares.

Atualmente, preconiza-se o uso de implantes bilaterais simultâneos ou sequenciais. Estudos mostraram que crianças com implante bilateral tem maior habilidade em localizar os sons e entendimento da linguagem em ambientes ruidosos, se comparados àquelas com implante unilateral ${ }^{[49,50]}$.

\subsection{RESPOSTAS AUDITIVAS DE ESTADO ESTÁVEL}

Inicialmente, as respostas auditivas de estado estável (RAEE) foram descritas com detalhes por Galambos et al. em $1981^{[51]}$. Neste estudo, os autores estudaram respostas de tronco encefálico e potenciais de média latência em $500 \mathrm{~Hz}$, observaram que as melhores respostas ocorriam na modulação de $40 \mathrm{~Hz}$, com as vantagens de obtenção de limiares próximo ao tonal, fáceis de se identificar e com boa amplitude.

As respostas de $40 \mathrm{~Hz}$ só podem ser obtidas em sujeitos acordados, pois apresentam como limitação a dependência do nível de consciência e sono ${ }^{[52,53]}$.

$\mathrm{O}$ uso das modulações entre 70 e $110 \mathrm{~Hz}$ mostraram a possibilidade de respostas confiáveis durante o sono ou anestesia, mesmo em intensidades menores.

Apesar de não bem compreendidas, as RAEE estão relacionados à geradores múltiplos de córtex e tronco encefálico. Quando evocado por taxas de estímulo superior a $60 \mathrm{~Hz}$, as contribuições são do complexo olivar superior, colículo inferior e núcleo coclear ${ }^{[54,55]}$.

As respostas, captadas por eletrodos de superfície, são em primeiro momento, analisadas no domínio do tempo e, a seguir, submetidas à Transformada Rápida de Fourier (FFT). Desta forma, as respostas podem ser analisadas no domínio da frequência de modulação, pois a resposta da frequência portadora gerada pelo sistema auditivo será detectada justamente na frequência de modulação ${ }^{[56]}$.

Rickards et al. (1994) ${ }^{[57]}$ estudaram neonatos em sono natural e sugeriram a possibilidade do uso da RAEE na triagem auditiva em berçários por considerarem a 
técnica rápida e confiável na aquisição do limiar eletrofisiológico nas modulações entre 60 e $100 \mathrm{~Hz}$.

Rance et al. (1995) ${ }^{[58}$ estudaram a RAEE em 60 indivíduos, entre adultos e crianças. Nas frequências de 250, 500, 1000, 2000 e $4000 \mathrm{~Hz}$, encontraram boa correlação entre a audiometria tonal e RAEE, principalmente nos pacientes com algum grau de perda auditiva. Observaram ainda, melhor correlação nas frequências agudas.

Como vantagem sobre os estímulos transientes do PEATE, Rance et al. (1995) ${ }^{[58]}$, ressaltaram que a característica de modulação da RAEE possibilitaria o uso de estímulos com intensidades de até $120 \mathrm{~dB}$ NA, dada a característica de modulação contínua da RAEE, o que permitiria a avaliação mais precisa e confiável de orelhas com audição residual e candidatos ao implante coclear ${ }^{[14]}$.

O tipo de modulação do estímulo permite ainda estimulação de múltiplas frequências simultaneamente em ambas orelhas, sem que haja prejuízo à amplitude das respostas, o que torna o exame atrativo do ponto de vista de tempo, quando comparado ao potencial evocado auditivo com estímulos transientes (tone burts, p. ex.), em que cada frequência deve ser apresentada separadamente em cada orelha ${ }^{[59]}$.

A análise da RAEE depende de métodos matemáticos e estatísticos, como coerência de fase ou análise da variância (teste F), para predizer se a amplitude da resposta é significantemente distinguível do ruído de fundo ${ }^{[60]}$.

Diversos estudos preocuparam-se em estimar a precisão da RAEE em comparação à configuração da audiometria e também com relação aos resultados obtidos por tone burst: Lins et al., $1996^{[16]}$ estudaram dez orelhas de adolescentes com perda auditiva neurossensorial documentada através de audiometria tonal e encontram coeficiente de correlação entre 0,7 e 0,9 , sendo maior nas frequências agudas. As diferenças são menores entre o limiar tonal e na RAEE em indivíduos com perda auditiva em comparação aos normouvintes. Tal achado estaria relacionado possivelmente ao fenômeno de recrutamento eletrofisiológico, que se traduz por respostas com amplitude proeminente em intensidades próximas ao limiar.

Os resultados obtidos por Lins et al. (1996) foram comprovado através de outros diversos estudos, tanto em adultos ${ }^{[16,58,61-68]}$ quanto em crianças ${ }^{[58,64,69]}$. 
Com relação às frequências, as maiores diferenças ocorrem em $500 \mathrm{~Hz}$, o que pode ser explicado entre outras razões, pela dificuldade de sincronização nas frequências graves, exibindo menor amplitude das respostas e pela desaceleração da chegada da onda viajante nas regiões mais apicais ${ }^{[16,58,59,61-64,70-73]}$.

Luts et al., $2004^{[74]}$ avaliaram 10 crianças entre 3 e 14 meses através de PEATE, RAEE e avaliação comportamental, nas frequências de 500, 1000, 2000 e 4000 Hz. Obtiveram correlação de 0,77 em 2KHz entre RAEE e PEATE e 0,92 entre RAEE e avaliação comportamental. Observaram que na avaliação dicótica de múltiplas frequências, há aumento da precisão na obtenção dos limiares, com consequente aumento do tempo de exame. Como em crianças o tempo de exame é muito importante, concluíram que a RAEE pode ser ferramenta confiável na avaliação eletrofisiológica.

Na comparação entre PEATE por clique com a RAEE em 2 e $4 \mathrm{KHz}$ e entre PEATE com tone burst em $500 \mathrm{~Hz}$ com a RAEE em 32 crianças entre 2 meses e 3 anos de idade, com perda auditiva, observaram-se coeficientes de correlação de 0,97 e 0,86 , respectivamente ${ }^{[75]}$.

A Meta-análise conduzida por Tlumak et al., $2007^{[76]}$, mostrou que o uso da RAEE é ferramenta confiável para avaliação de indivíduos com ou sem perda auditiva e também concluíram que há maior diferença entre o limiar tonal e por RAEE em $500 \mathrm{~Hz}$.

\subsection{AVALIAÇÃO DE AUDIÇÃO RESIDUAL ATRAVÉS DAS RESPOSTAS AUDITIVAS DE ESTADO ESTÁVEL}

Rance et al., $1995^{[58]}$, avaliaram adultos e crianças entre normouvintes, com diferentes graus de perda auditiva e com perda profunda, nas frequências entre $250 \mathrm{e}$ $4000 \mathrm{~Hz}$. Observaram que a correlação entre os limiares tonais e às RAEE é tanto melhor, quanto pior a perda auditiva, assim como nas frequências mais altas.

$\mathrm{Na}$ avaliação de perdas severas e profundas, Rance et al. (1998) ${ }^{[15]}$, confirmaram a vantagem da RAEE sobre o PEATE. Foram avaliadas 108 crianças 
entre 1 e 49 meses com ausência de respostas no PEATE a 100 dB NA. Naqueles indivíduos com RAEE ausente na máxima intensidade de estimulação, 99,5\% também tinham perda total de audição ou limiar comportamental até $10 \mathrm{~dB}$ melhor. A maioria das respostas obtidas foram em 500 e $1000 \mathrm{~Hz}$ em 120 dB NA às RAEE. Em 99\% das comparações entre RAEE e avaliação comportamental, os limiares tinham diferença menor ou igual a $20 \mathrm{~dB}$. Ainda, concluíram que a ausência de respostas à RAEE seria indicador confiável de surdez profunda.

Rance e Briggs (2002) ${ }^{[69]}$ avaliaram 200 crianças entre 1 e 8 meses (média $=$ 3 meses) que falharam na avaliação com PEATE automático evocado por cliques (limiar superior a $40 \mathrm{~dB} \mathrm{HL}$ ). Foram incluídas aquelas que mostraram limiar ao ASSR > $60 \mathrm{~dB}$ NA em qualquer frequência testada. Obtiveram coeficiente de correlação entre 0,81 e 0,93 nas frequências portadoras comparando-se RAEE e avaliação subjetiva. Entre os avaliados, 3\% apresentavam ausência de respostas em todas as frequências. Concluíram que a ausência de respostas ao ASSR seria um forte indicador de ausência de audição residual e amplificável.

Vander Werff et al. (2002) ${ }^{[75]}$ avaliaram 31 orelhas de crianças entre 2 meses e 3 anos. Comparando os limiares à RAEE na média entre 2000 e $4000 \mathrm{~Hz}$ com PEATE clique a correlação foi de 0.97. Quando comparado o limiar à RAEE em $2000 \mathrm{~Hz}$ com o clique, a correlação foi de 0.96 . Na comparação entre tone burst de $500 \mathrm{~Hz}$ e RAEE em $500 \mathrm{~Hz}$, a correlação foi de 0.86 .

Roberson et al. (2003) ${ }^{[77]}$, avaliaram 20 crianças. Observaram respostas à RAEE em pelo menos duas frequências em $65 \%$ dos pacientes com ausência de respostas no PEATE clique e concluíram tratar-se de opção vantajosa na avaliação pré-implante coclear.

Estudo de Swanepoel e Hugo (2004) ${ }^{[14]}$ com 15 crianças entre 10 e 60 meses compararam avaliação comportamental em campo aberto, PEATE e RAEE. Dos limiares obtidos à RAEE. 92\% foram em intensidades superiores ao limite do PEATE clique (90 dB NA), sendo que a frequência de $2000 \mathrm{~Hz}$ foi aquela com maior quantidade de respostas. 
Ainda, Swanepoel et al. (2004) ${ }^{[78]}$, compararam limiares tonais e RAEE em 10 crianças entre 10 e 15 anos com perda severa a profunda. A melhor correlação obtida foi em $1000 \mathrm{~Hz}(0,75)$ e a pior em $500 \mathrm{~Hz}(0,58)$.

Lee et al. (2004) ${ }^{[79]}$, na avaliação entre audiometria e RAEE de 22 sujeitos com perda auditiva severa a profunda, encontraram coeficientes de correlação entre 0,94 e 0,91 nas frequências de 500,1000, 2000 e $4000 \mathrm{~Hz}$.

Firszt et al., (2004) ${ }^{[13]}$, avaliaram 42 crianças entre 1 e 54 meses com PEATE ausente através de RAEE. Concluíram que a associação entre os métodos poderia trazer informações importantes tanto para protetização quanto para implante coclear. Trinta e oito porcento das crianças foram implantadas com sucesso. Destacaram a importância da RAEE como ferramenta objetiva na avaliação de resíduos auditivos.

Beck et al., (2011) ${ }^{[80]}$, avaliaram a presença de audição residual através da RAEE em crianças candidatas a implante coclear $(n=35)$. As respostas foram obtidas em $57 \%$ das orelhas em pelo menos uma frequência, sendo a maioria delas em 500 Hz. Concluíram que a RAEE pode fornecer informações adicionais sobre a audição residual em crianças candidatas a implante coclear.

$\mathrm{Na}$ comparação entre RAEE em altas intensidades e avaliação comportamental instrumental, Beck et al. (2012) ${ }^{[81]}$ avaliaram 42 crianças candidatas a implante coclear entre 3 e 72 meses. Em 7 das 42 crianças avaliadas apesar da ausência de respostas à RAEE, foram detectadas respostas à avaliação subjetiva em todas as faixas de frequências avaliadas. Não foram observadas RAEE falso-positiva.

À medida em que a idade de indicação de implante coclear diminui, a avaliação precisa dos limiares por métodos eletrofisiológicos torna-se mais importante. Segundo Rance et al., $1998^{[15]}$; Rance e Rickards, 2002 ${ }^{[82]}$ e Roberson et al., 2003 ${ }^{[77]}$ os limiares obtidos na RAEE são precisos o suficiente para guiar a adaptação de próteses auditivas e indicar o implante coclear, mesmo sem os testes de percepção de fala, principalmente em crianças.

Entretanto, a estimulação em altas intensidades pode produzir artefatos eletroencefalográficos, tanto por via aérea quanto por via óssea, que podem ser interpretados de maneira errônea como resposta biológica. 
Picton e John (2004) ${ }^{[83]}$ consideraram que os tipos de artefatos variam com o transdutor e o tipo de fone. A estimulação por via óssea geraria maior quantidade de artefatos assim como os fones do tipo casco.

$\mathrm{Na}$ avaliação do uso das RAEE na intensidade máxima de estimulação de 120 dB HL, Small e Stapells (2004) ${ }^{[84]}$ observaram respostas espúrias por via aérea em 500 e $1000 \mathrm{~Hz}$ em indivíduos com perda profunda que não ouviram os estímulos com a oclusão dos fones de inserção.

Gorga et al. (2004) ${ }^{[85]}$ utilizaram estímulo em intensidade máxima para cada frequência (entre $118 \mathrm{~dB} \mathrm{HL}$ para $500 \mathrm{~Hz}$ e 122 para $4000 \mathrm{~Hz}$ ) e observaram respostas em todas as frequências em todos os indivíduos, sem respostas na avaliação audiométrica. Sugeriram que tais respostas não refletem o sistema auditivo periférico, sendo resultado de artefatos do estímulo ou do equipamento. Consideraram que medidas confiáveis não podem ser feitas em intensidades superiores a $100 \mathrm{~dB}$ NA.

A detecção de tais problemas levaram Picton e John $(2004)^{[83]}$ a proporem que tais artefatos poderiam ser evitados com filtros, empregando taxas de conversão analógico-digitais não submúltiplos da frequência portadora e utilizando tons modulados em amplitude com polaridade que se alterna a cada ciclo de frequência de modulação. Relataram que tais correções elimianaram respostas artefatuais no sistema MASTER do equipamento Bio-logic Navigator Pro (Natus Medical Incorporated, Mundelein, Il).

Ainda, não se pode afastar a possibilidade de artefatos não auditivos somatossensoriais, principalmente na estimulação de 250 e $500 \mathrm{~Hz}{ }^{[15]}$. Estímulos auditivos de altas intensidades poderiam ativar aferências vestibulares no sáculo que evocariam potenciais miogênicos captados no músculo esternocleidomastoideo ${ }^{[86]}$, mesmo na perda auditiva profunda ${ }^{[87]}$.

Após um longo período sem publicações à respeito da estimulação das altas intensidades nas RAEE, Ramos (2013) ${ }^{[20]}$ e Ramos et al. $2015^{[88]}$ estudaram 40 indivíduos entre 15 e 63 anos, candidatos ao implante coclear. Foram comparados os resultados da audiometria tonal e a presença de resíduos auditivos com as RAEE, nas intensidades máximas de estimulação nas frequências de 500, 1000, 2000 e $4000 \mathrm{~Hz}$. 
Obtiveram limiares mensuráveis em $62,5 \%$ das frequências estudadas na audiometria tonal e 63,1\% nas RAEE. Para a detecção da audição residual, apresentaram sensibilidade de 96\% e especificidade de 91,6\%. Em nenhuma das frequências houve diferença estatisticamente significativa entre os limiares por RAEE e audiometria tonal.

\subsection{AVALIAÇÃO AUDITIVA COMPORTAMENTAL}

Audição é uma atividade cognitiva e por isso métodos eletrofisiológicos devem ser comparados aos métodos subjetivos, que são considerados padrão-ouro [89].

A audiometria de reforço visual (VRA) é uma modificação da audiometria tonal convencional desenhada para crianças que não conseguem responder às ordens verbais. Na VRA, as técnicas de condicionamento são utilizadas para recompensar as crianças quando elas apresentam respostas naturais (virar a cabeça), frente a um estímulo sonoro.

Ao movimentar a cabeça em resposta ao estímulo, a criança se depara com um brinquedo piscando, p.ex., e isso estimula que ela continue participando ${ }^{[90,91]}$.

Matkin $197{ }^{[92]}$ verificou que a VRA apresenta uma taxa de sucesso de $90 \%$, tanto em crianças com audição normal quanto naquelas com comprometimento auditivo entre 12 e 30 meses.

Wilson e Thompson (1984) ${ }^{[93]}$ estabeleceram limiares auditivos em 90 lactentes entre 5 e 18 meses. Gravel e Traquina (1992) ${ }^{[94]}$ utilizaram VRA para avaliar a audição de 211 crianças entre 6 e 24 meses, obtendo limiares frequência específicos em mais de $80 \%$ delas.

Talbot (1987) ${ }^{[95]}$ comparou de maneira longitudinal os resultados obtidos na VRA entre 6 e 24 meses e depois dos 25 aos 41 meses através de audiometria condicionada. Obteve resultados semelhantes que lhe permitiram indicar que a VRA poderia identificar o nível mínimo de resposta de maneira fidedigna o suficiente para adaptação de próteses auditivas e terapia fonoaudiológica. 
De acordo com Lopes Filho (1994) ${ }^{[96]}$ e Russo e Santos (1994) ${ }^{[97]}$, as técnicas de avaliação infantil deveriam ser simples, fáceis de serem realizadas e flexíveis o suficiente para se adequarem às necessidades específicas de cada criança. Lopes Filho (1994) ${ }^{[96]}$ também alertou que os procedimentos durante a avaliação são influenciados pela prática e experiência do examinador e, principalmente, pelo comportamento da criança. Há diversos fatores que podem dificultar ou facilitar a realização da avaliação tais como o desenvolvimento neuropsicomotor, a aquisição da fala e o grau de desenvolvimento de linguagem da criança.

De acordo com Russo e Santos (1994) ${ }^{[97]}$, um fator decisivo na avaliação comportamental é o conhecimento do aspecto acústico do estímulo sonoro utilizado. Estes estímulos poderiam ser classificados em instrumentos geradores de ruídos (não-calibrados) e instrumentos eletrônicos geradores de sons calibrados. Segundo as autoras, a vantagem dos sons calibrados seria a possibilidade de manusear a intensidade e poder repetir o som quantas vezes forem necessárias, sem alterações das características acústicas.

Azevedo (1997) ${ }^{[11]}$ descreveu uma rotina de atendimento audiológico para bebês. Nessa rotina estariam incluídos: anamnese, observação do desenvolvimento global e das respostas comportamentais à estímulos sonoros, audiometria com reforço visual, observação das respostas à estímulos verbais (reação à voz, detecção da voz, reconhecimento de comandos verbais) e avaliação das condições da orelha média.

Nielsen e Olsen (1997) ${ }^{[98]}$ avaliaram 294 crianças através de VRA, audiometria orientada por reflexos e audiometria condicionada. Observaram que a partir dos 2 anos de idade, 50\% das crianças foram capazes de responder e determinar limiares em pelo menos 3 frequências e que a partir dos 3 anos, 75\% já conseguiam estabelecer 6 limiares. Reforçam que deveria ser realizado cross-check entre métodos subjetivos e objetivos.

Widen et al. (2000) ${ }^{[99]}$ avaliaram mais de 3000 crianças entre 8 e 12 meses de idade e encontraram nível mínimo de respostas confiáveis em 95\% delas.

Day et al. (2000) ${ }^{[100]}$ mostraram que o uso de fones de inserção é possível já a partir dos 6 meses de idade, nem que para isso sejam necessárias várias sessões. 
Apesar dos autores supracitados, Williamson (2002) ${ }^{[12]}$ colocou que a avaliação auditiva comportamental tem confiabilidade limitada, no qual alguns bebês parecem responder sem ouvir e outros ouvem e não respondem. No entanto, reconhece que a avaliação é de grande valia para obtenção de informações frequência específicas, pode ainda fornecer informações nas disfunções neurológicas com PEATE duvidoso e também demonstrar os benefícios da amplificação.

Parry et al. (2003) ${ }^{[101]}$ estudaram os níveis mínimos de respostas (MRL) em crianças normouvintes e compararam-as com os adultos. Concluíram que existe diferença entre os valores, principalmente em frequências graves e que para uma eventual intervenção com prótese auditiva, fatores de correção deveriam ser utilizados. Como causa, sugeriram fatores sensoriais e não-sensoriais, entre eles: impedância da orelha média, ruído corporal, relação sinal-ruído, assim como, tipo de teste aplicado e atenção da criança.

Widen et al. (2005) ${ }^{[102]}$ observaram que a maioria das crianças testadas entre 8 e 12 meses, apresentavam respostas confiáveis. Dois terços delas, conseguiram concluir a VRA com fones de inserção entre 20 e 30 minutos.

O tipo de estímulo mais aplicado é o tom puro modulado em frequência (Warble), que facilita a percepção do som para determinação do nível mínimo de resposta ${ }^{[103]}$. 
MATERIAL E MÉTODOS 


\section{MATERIAL E MÉTODOS}

Entre junho de 2012 e junho de 2013, foram avaliadas 76 crianças com suspeita de perda auditiva, provenientes do Ambulatório do Grupo de Implante Coclear do Hospital das Clínicas da Faculdade de Medicina da Universidade de São Paulo.

\subsection{ASPECTOS ÉTICOS}

A pesquisa foi aprovada pela Comissão de Ética para Análise de Projetos de Pesquisa (CAPPesq), da Diretoria Clínica do HC-FMUSP sob o número 41225/2012 - Anexo A.

Cadastrada e Aprovada na Plataforma Brasil, sob o número 38954 (20/06/2012) - Anexo B.

\subsection{CASUÍSTICA}

\subsubsection{CRITÉRIOS DE INCLUSÃO}

Todos os pais e/ou responsáveis legais foram esclarecidos a respeito dos exames a serem realizados e assinaram Termo de Consentimento Informado (Anexo C).

Foram incluídos pacientes com faixa etária entre 6 meses e 6 anos de idade, com suspeita de surdez severa e/ou profunda em protocolo de avaliação do Grupo de Implante Coclear do HC-FMUSP ${ }^{[8,9]}$ que apresentavam:

- Ausência de respostas ao PEATE com cliques por via aérea em 90 dB NA e por via óssea em $55 \mathrm{~dB}$ NA

- Ausência de respostas às emissões otoacústicas por produtos de distorção (EOA PD) na maioria das frequências testadas entre 750 e $8000 \mathrm{~Hz}$. 
- Otomicroscopia normal bilateralmente, no dia do exame.

\subsubsection{CRITÉRIOS DE EXCLUSÃO}

- Pacientes com suspeita de Doença do Espectro da Neuropatia Auditiva PEATE com ausência de respostas, emissões otoacústicas presentes e/ou presença de microfonismo coclear

- Doenças de orelha média (otite média secretora, otite média crônica, malformações de orelha média)

- Agenesia de nervo coclear ou malformação coclear diagnosticados previamente por Ressonância nuclear magnética e/ou Tomografia Computadorizada de ossos temporais.

- Pacientes que não completaram a avaliação comportamental (doenças neurológicas, psiquiátricas, entre outras)

- $\quad$ Nível de ruído eletroencefalográfico superior a 30 nanoVolts $(\mathrm{nV})^{[72]}$

Foram avaliados 63 pacientes (Figura 1).

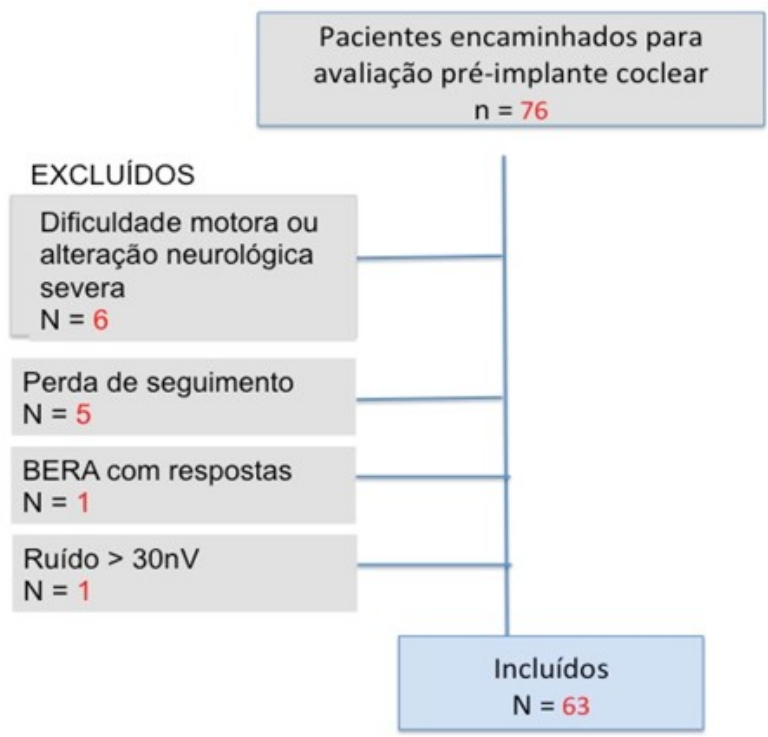

Figura 1 - Organograma com a aplicação dos critérios de exclusão 


\subsection{MÉTODOS}

Os pais e/ou responsável legal foram entrevistados pelo examinador antes do exame, visando obtenção de dados quanto a gestação, parto, pós-natal, antecedentes familiares, exames previamente realizados (Anexo D).

As crianças foram submetidas à bateria de exames eletrofisiológicos em uma única sessão sob anestesia geral inalatória, de acordo com procedimento padrão do Setor de Eletrofisiologia da Audição e é assistido por médico anestesista contratado da Divisão de Anestesiologia do HC-FMUSP. Como agente anestésico foi utilizado o Sevoflurane em dose suficiente para manutenção de hipnose.

Já com a criança anestesiada, foi realizada otomicroscopia com visualização de conduto auditivo externo e membrana timpânica, utilizando-se de Microscópio binocular modelo M9000 (DF Vasconcelos, Valença - RJ) com objetiva de $200 \mathrm{~mm}$. Em caso de presença de cerume e/ou descamação epitelial, estes foram removidos para completa visualização da membrana timpânica e garantia da permeabilidade do conduto auditivo externo, evitando obstrução da sonda dos fones de inserção.

\subsubsection{RESPOSTAS AUDITIVAS DE ESTADO ESTÁVEL}

A medida da RAEE foi obtida utilizando o software Multiple Auditory Steady-State Responses (MASTER) 2.04.i00 do sistema Bio-logic Navigator Pro (Natus Medical Incorporated, San Carlos, CA).

Os estímulos empregados para evocar a RAEE foram tons contínuos sinusoidais modulados $100 \%$ em amplitude exponencial e $20 \%$ em frequência, com fase da frequência de modulação em $-90^{\circ}$.

Os estímulos foram apresentados através de fones de inserção (ER-3A), nas frequências portadoras de 500, 1000, 2000 e $4000 \mathrm{~Hz}$, com estimulação dicótica de uma única frequência. A frequência de modulação foi escolhida de acordo com o protocolo padrão do equipamento, em $66,797 \mathrm{~Hz}$ para a orelha esquerda e $69,141 \mathrm{~Hz}$ para a orelha direita. O nível máximo de intensidade da estimulação foi de $110 \mathrm{~dB}$ NA para todas as frequências $(500,1000,2000$ e $4000 \mathrm{~Hz})$. 
Foram utilizados eletrodos de superfície dispostos na fronte alta $(\mathrm{Fz})$ como eletrodo ativo, na nuca $(\mathrm{Oz})$ como referência e no ombro direito $(\mathrm{Pz})$ como terra. Previamente à fixação dos eletrodos, foi realizada a limpeza da pele com pasta abrasiva (Nuprep $\left.{ }^{\circledR}\right)$. Os eletrodos foram posicionados na pele com pasta condutora (Ten20®) e fixados com fita adesiva. A impedância dos eletrodos foi mantida abaixo de $5 \mathrm{kOhm}$.

A atividade elétrica registrada foi composta pelo sinal do EEG (ruído) e da resposta evocada pelo estímulo auditivo (sinal). Os dados foram armazenados em segmentos de 1,024 segundo de duração (epochs). Foram coletados 16 segmentos consecutivos de informações, combinados para formar uma varredura. O número máximo de varreduras foi determinado de acordo com a intensidade do estímulo. Nas intensidades entre 100 e $110 \mathrm{~dB}$ NA foram utilizadas 10 varreduras. Entre 90 e $99 \mathrm{~dB}$ NA, 12 varreduras foram coletadas e na faixa entre 80 e 89 dB NA, 18 varreduras, de acordo com protocolo padrão do equipamento.

Uma vez completa, cada varredura foi rateada no domínio de tempo e, subsequentemente, submetida à Transformada Rápida de Fourier. $\mathrm{O}$ espectro de amplitudes resultante permitiu que a RAEE fosse analisadas no domínio de frequência. Desta forma, a resposta auditiva pôde ser detectada na mesma frequência de modulação correspondente à frequência portadora (Figuras 2-5).

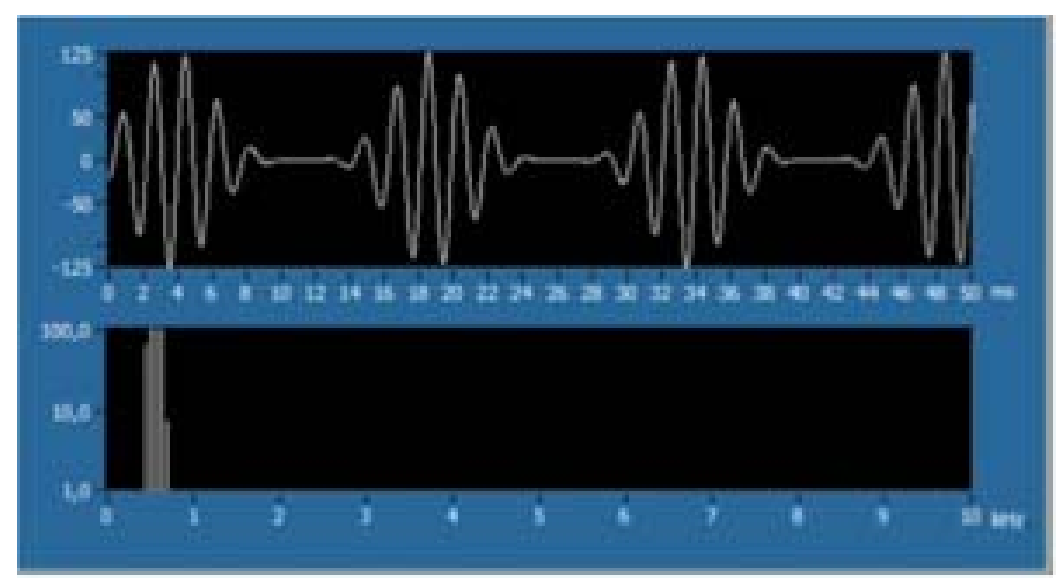

Figura 2 - Tom contínuo sinusoidal para frequência portadora de $500 \mathrm{~Hz}$ 


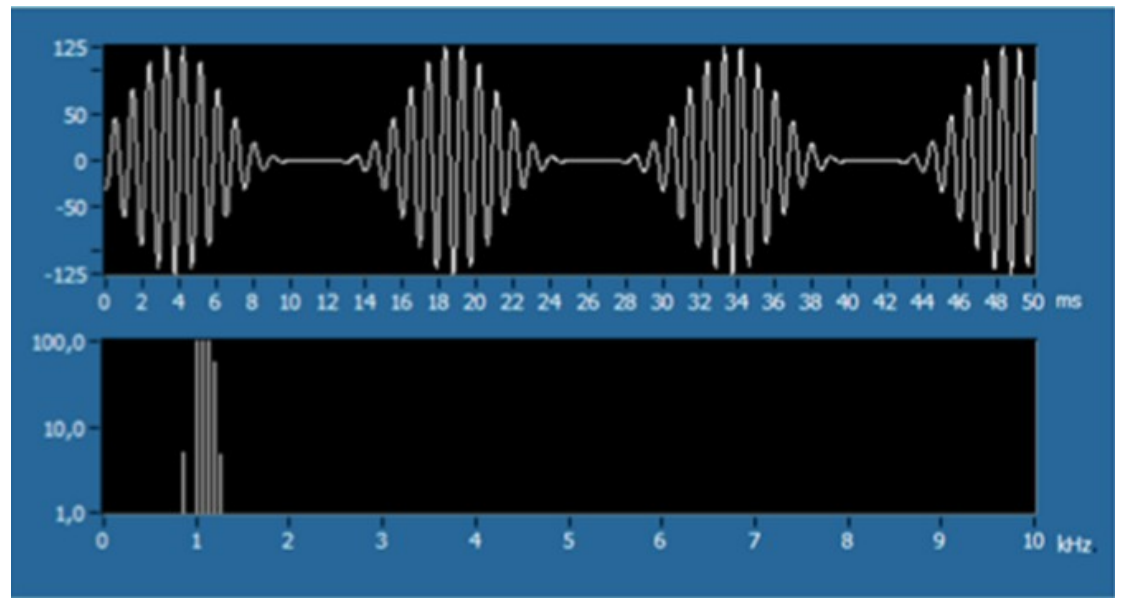

Figura 3 - Tom contínuo sinusoidal para frequência portadora de $1000 \mathrm{~Hz}$

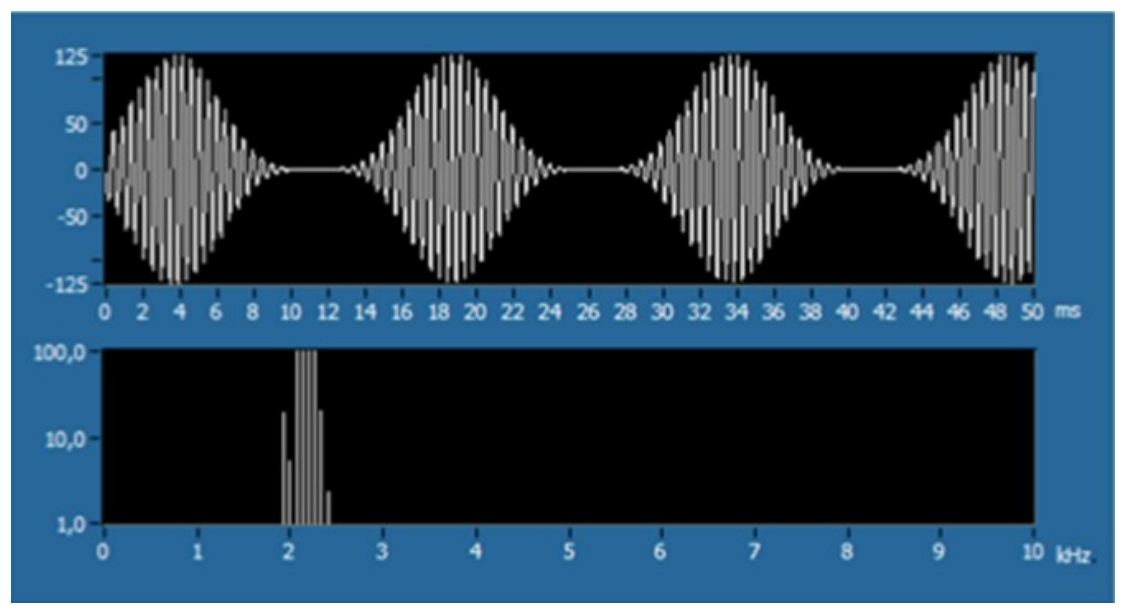

Figura 4 - Tom contínuo sinusoidal para frequência portadora de $2000 \mathrm{~Hz}$

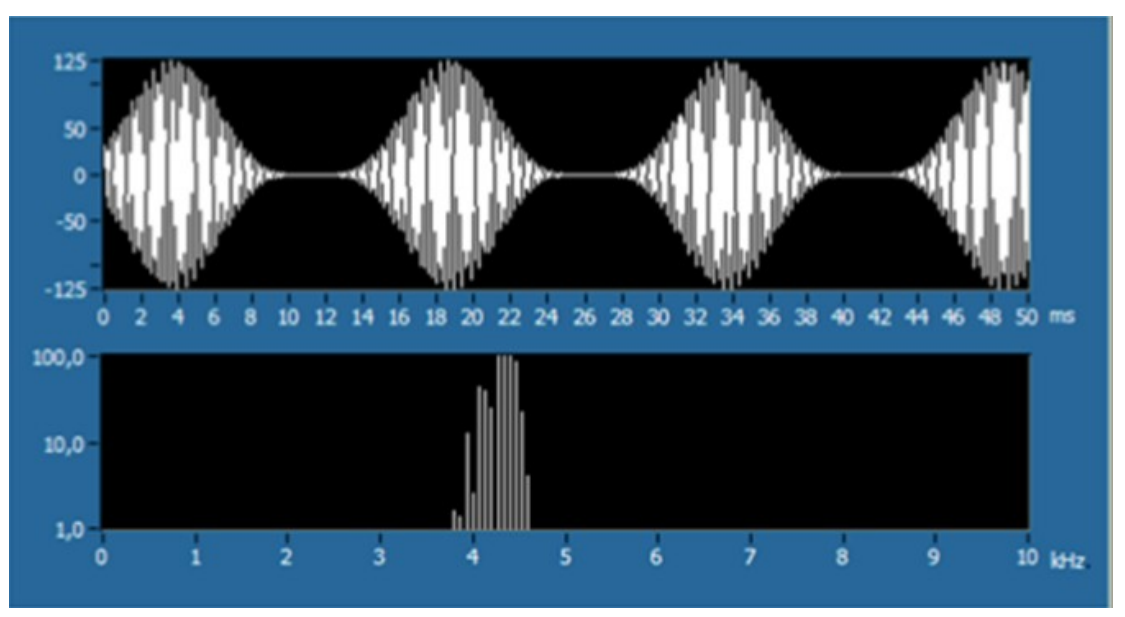

Figura 5 - Tom contínuo sinusoidal para frequência portadora de $4000 \mathrm{~Hz}$ 
O espectro de frequências foi analisado automaticamente pelo "software, determinando se a amplitude da resposta para uma determinada frequência de modulação foi diferente da amplitude do ruído de fundo eletroencefalográfico nas frequências adjacentes. A verificação do nível de significância da relação sinal-ruído foi realizada pela aplicação do teste F com intervalo de confiança de 95\%. A resposta foi considerada presente quando o valor $F$ era significante em um nível de $p<0,05$. $O$ valor-F entre 0,05 e 0,1 sugere resposta duvidosa. As respostas foram consideradas ausentes quando a relação sinal-ruído não alcançou significância $(\mathrm{p}<0,05)$ após o número máximo de varreduras.

Os estímulos foram apresentados a uma intensidade inicial de $110 \mathrm{~dB}$ NA simultaneamente em ambas as orelhas, uma frequência por vez. A primeira frequência testada foi $500 \mathrm{~Hz}$, seguido por 1000, 2000 e $4000 \mathrm{~Hz}$ (Figura 6).

Os limiares foram determinados com pesquisa descendente de $10 \mathrm{~dB}$ e confirmados, até que todas as respostas estivessem ausentes. Para cada nível de intensidade, foi respeitado o número máximo de varreduras e para a resposta ser considerada como presente, esta manteve significância $(p<0,05)$ por 4 ou mais varreduras consecutivas ${ }^{[72]}$. Todos os limiares foram confirmados com a repetição do teste. A ausência de respostas também foi confirmada com a repetição do teste. $O$ limiar na RAEE foi definido como a menor intensidade na qual uma resposta significante foi detectada. 


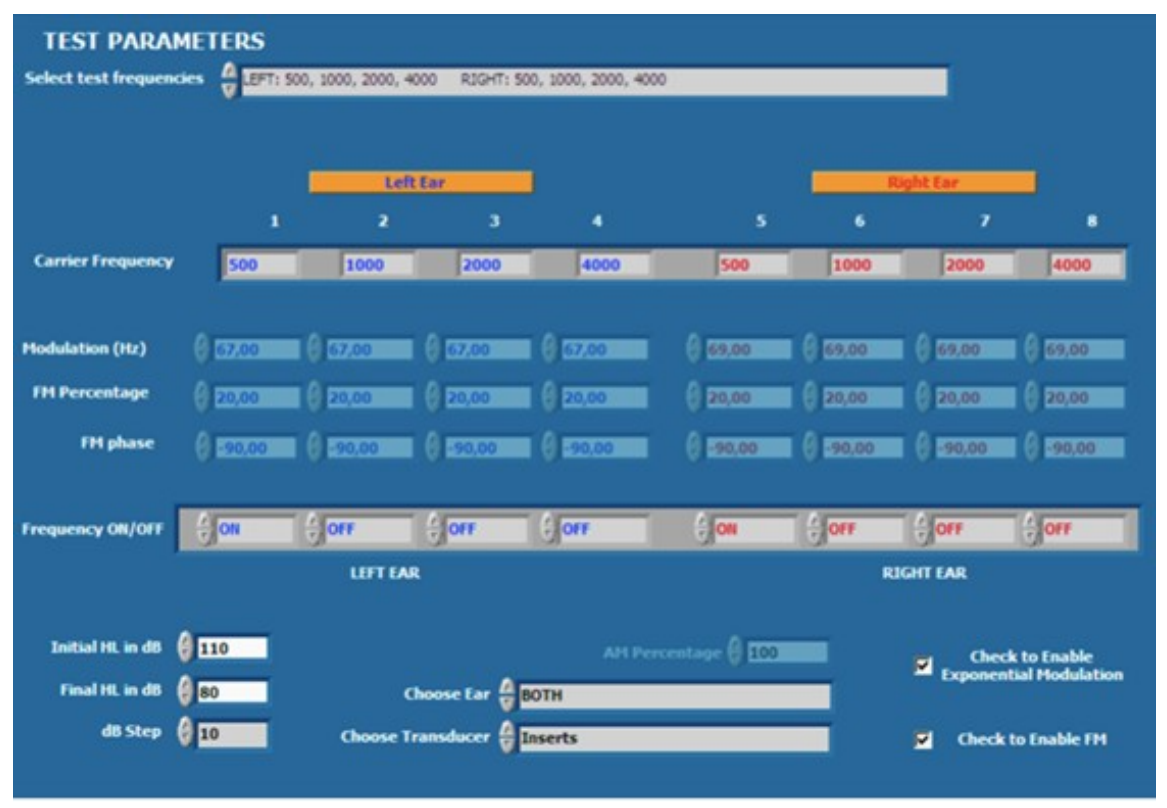

Figura 6 - Seleção de estímulos e parâmetros no "software" Multiple Auditory Steady-State Responses (MASTER) 2.04.i00 do sistema Bio-Logic Navigator Pro 
Conforme a Figura 7, a atividade do EEG é expressa no canto superior esquerdo em microvolts $(\mu \mathrm{V})$. No canto superior direito, observa-se o espectro de amplitudes no domínio da frequência em nanoVolts $(\mathrm{nV})$, após a aplicação da FFT. A resposta da orelha direita é notada pelo pico da amplitude em 69,141 $\mathrm{Hz}$ e a ausência de resposta a esquerda pela ausência de diferença entre a resposta na frequência de modulação de 66,797 Hz e o ruído EEG nas frequências adjacentes. As varreduras que continham ruído eletrofisiológico superior a $90 \mathrm{nV}$, foram rejeitadas ${ }^{[64]}$.

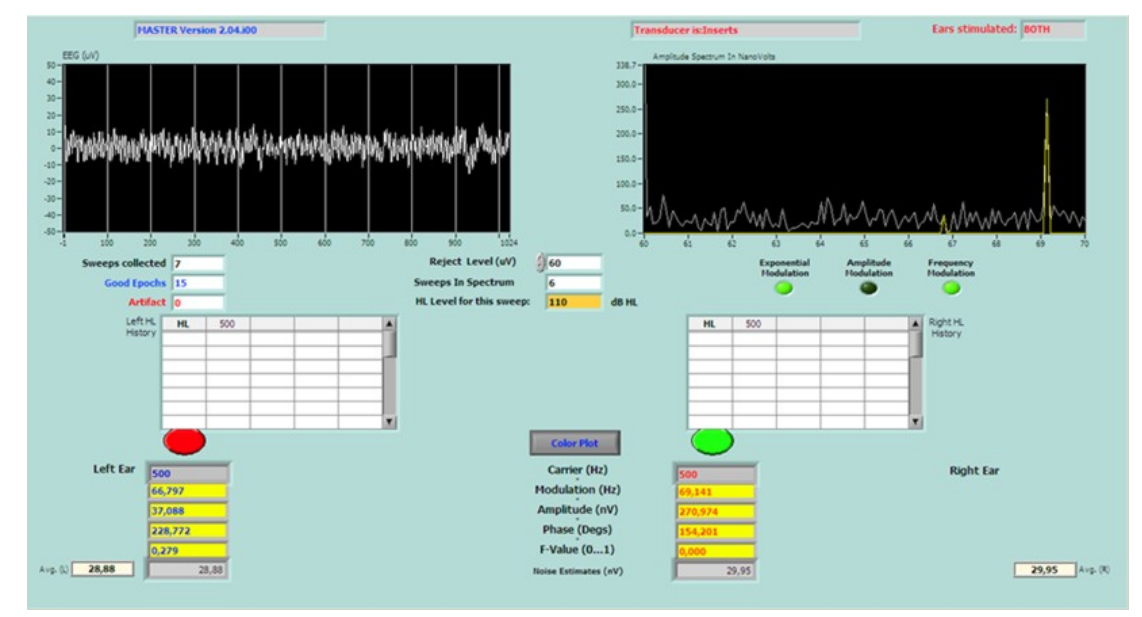

Figura 7 - Registro da RAEE no "software" MASTER 2.04.i.00 do Sistema BioLogic Navigator Pro na frequência portadora de $500 \mathrm{~Hz}$ 
Os limiares obtidos foram selecionados para a composição do audiograma eletrofisiológico. Não foram utilizados os índices de correção padronizados pelo "software" (Figura 8).

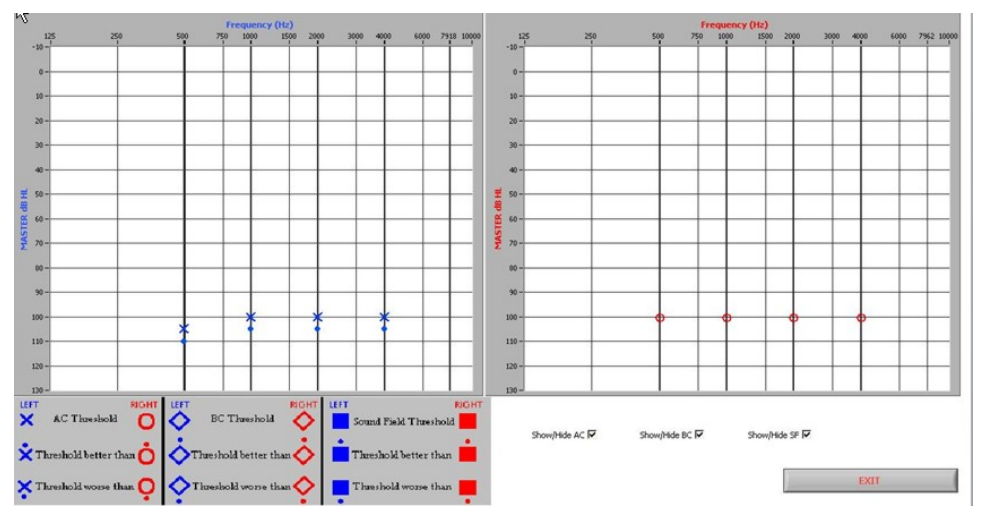

Figura 8 - Audiograma eletrofisiológico com as respostas obtidas nas frequências em ambas as orelhas 


\subsubsection{AVALIAÇÃO COMPORTAMENTAL}

A avaliação audiológica comportamental foi realizada por duas ou mais fonoaudiólogas do Grupo de Implante Coclear e a definição do tipo de avaliação, foi definida de acordo com a faixa etária e capacidade de colaboração da criança.

Previamente, os examinadores realizaram meatoscopia, para evitar que cerúmen ou descamação no conduto auditivo externo e/ou eventuais alterações da membrana timpânica (p. ex. perfuração, otorréia), pudessem prejudicar a avaliação.

Em sala acusticamente tratada, silenciosa e com pouca luminosidade, a criança bem acordada, foi posicionada no colo do responsável ou em uma cadeira alta, em frente a um examinador. A organização da sala foi fator importante para manter a atenção da criança. O examinador foi o responsável em manter a atenção e postura da criança, utilizando-se de um brinquedo de entretenimento que não foi manipulado pela criança (Figura 9).

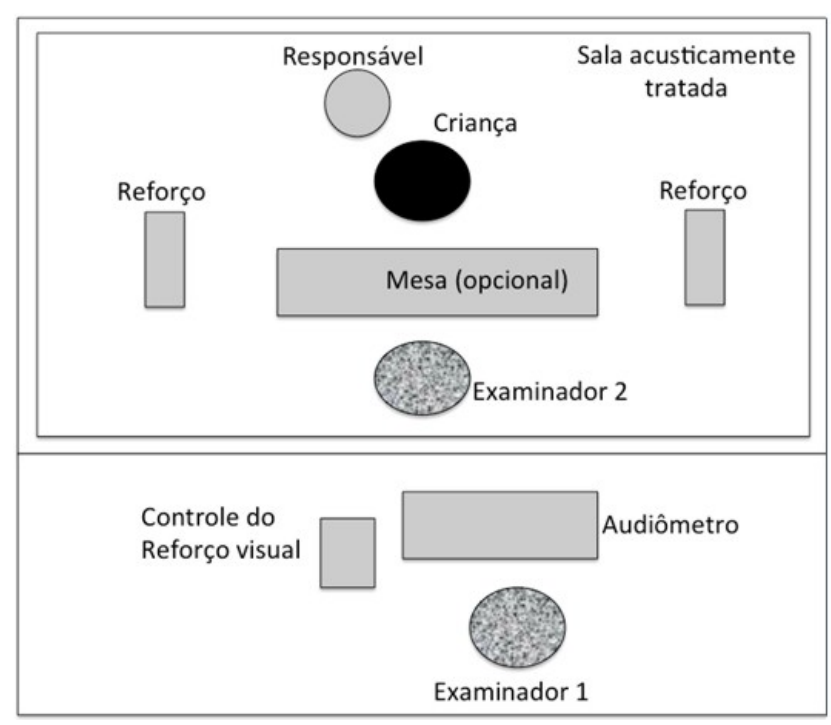

Figura 9 - Modelo esquemático da montagem da sala para avaliação comportamental 
Antes do início do teste, a família foi orientada a não influenciar e/ou estimular as respostas da criança, mantendo-a interessada durante todo o teste.

Para a avaliação auditiva comportamental, foi utilizado o audiômetro de 2 canais Interacoustics AC33 (Assens, Dinamarca). O estímulo escolhido foi o tom puro, modulado em frequência (Warble), oferecido através de fones de inserção EAR-tone 5A (Etymotic Research, Elk Grove Village, IL) ou fones supra-aurais TDH-39 (Telephonics Corporation Huntington, NY), calibrados de acordo com ISO 389-1 (TDH-39) e ISO 389-2 (EAR-5A).

Com o objetivo de familiarizar a criança com o teste, os estímulos e o reforço visual foram apresentados previamente.

Os estímulos foram apresentados em intensidades descendentes, de acordo com suas respostas. Foram testadas as frequências de 500, 1000, 2000 e $4000 \mathrm{~Hz}$, em cada orelha separadamente. Sempre que possível, iniciou-se com $500 \mathrm{~Hz}$ e $2000 \mathrm{~Hz}$ e posteriormente com as outras frequências ${ }^{[97]}$.

Os estímulos foram apresentados, preferencialmente, através de fones de inserção, por 2 a 3 segundos. $\mathrm{O}$ avaliador em frente ao paciente julgou se a resposta foi sistemática. As respostas foram retestadas para confirmação e foram consideradas positivas, quando a criança respondeu pelo menos 2 vezes em 3 tentativas.

Para as crianças entre 6 meses e 1 ano, observou-se as respostas comportamentais, principalmente, mudança na sucção, choro ou até procura da fonte sonora. A seguir, acendeu-se a luz do brinquedo como recompensa. A intensidade de estimulação foi diminuída gradualmente à procura do nível mínimo de resposta.

Para os maiores de 1 ano, a resposta esperada foi a procura da fonte sonora com a movimentação cefálica. Nessa faixa etária foram utilizados brinquedos para entretenimento ou no caso das crianças maiores e mais colaborativas, foi utilizado brinquedo de encaixe (técnica de condicionamento). A criança foi orientada a encaixar peças no brinquedo toda vez que percebesse o estímulo sonoro.

Já as crianças com bom grau de compreensão e colaboração foram orientadas a levantar a mão quando ouvissem o estímulo, seguindo a técnica de audiometria convencional. 


\subsection{ANÁLISE DOS DADOS}

Os dados coletados foram armazenados em banco de dados (Anexos E e F) e analisados no "software" SPSS 20.0 (IBM, Armonk, NY) para Windows ${ }^{\mathrm{R}}$ (Microsoft, Redmond, WA).

Inicialmente, foram criadas categorias de intensidade dos estímulos apresentados com as respectivas respostas dos pacientes, divididos em: ausentes, presentes entre 90 e $110 \mathrm{~dB}$ NA (faixa de perda auditiva profunda) e presentes em intensidade $<90 \mathrm{~dB}$ NA (perda auditiva severa ou melhor).

Para a análise estatística foi calculado o Kappa ponderado para avaliar a concordância entre os métodos. Foram calculadas as medidas diagnósticas (sensibilidade, especificidade), tendo a audiometria com reforço visual como padrão ouro para a presença e ausência de respostas em cada frequência testada.

Os resultados foram ilustrados com uso de gráficos de barras representando os percentuais de respostas em cada categoria de intensidade para cada método e os testes foram realizados com nível de significância de 5\%. 
Resultados 34

\section{RESULTADOS}

\subsection{CARACTERÍSTICAS DA AMOSTRA}

Foram recrutadas inicialmente, 76 crianças para este estudo. Destas, 13 foram excluídas, sendo 6 devido à alterações neurológicas ou motoras severas que impediram a avaliação comportamental, 5 por perda de seguimento, 1 por presença de respostas ao PEATE e uma por não atingir ruído eletroencefalográfico inferior a $30 \mathrm{nV}$.

Portanto, foram avaliadas 63 crianças, 33 do sexo masculino e 30 do sexo feminino. A faixa etária avaliada variou entre 6 a 72 meses de idade (média $=29,1 \pm$ $13,5)$. 


\subsection{RESPOSTAS OBTIDAS NA AUDIOMETRIA COM REFORÇO VISUAL (VRA)}

Foram obtidos limiares mensuráveis em 185 das 504 frequências testadas (36,7\%), na audiometria com reforço visual. A maioria das respostas foi obtida em $500 \mathrm{~Hz}$, diminuindo progressivamente nas frequências mais agudas.

Não houve diferença estatisticamente significativa entre as orelhas direita e esquerda.

$\mathrm{Na}$ frequência de $500 \mathrm{~Hz}$, foram obtidas 58 respostas, 56 na frequência de $1000 \mathrm{~Hz}, 39$ em $2000 \mathrm{~Hz}$ e 22 em $4000 \mathrm{~Hz}$. Ausência de respostas foi observada em 58 testes em 500 Hz, 70 em 1000 Hz, 87 em 2000 Hz e 104 em 4000 Hz (Gráfico 1).

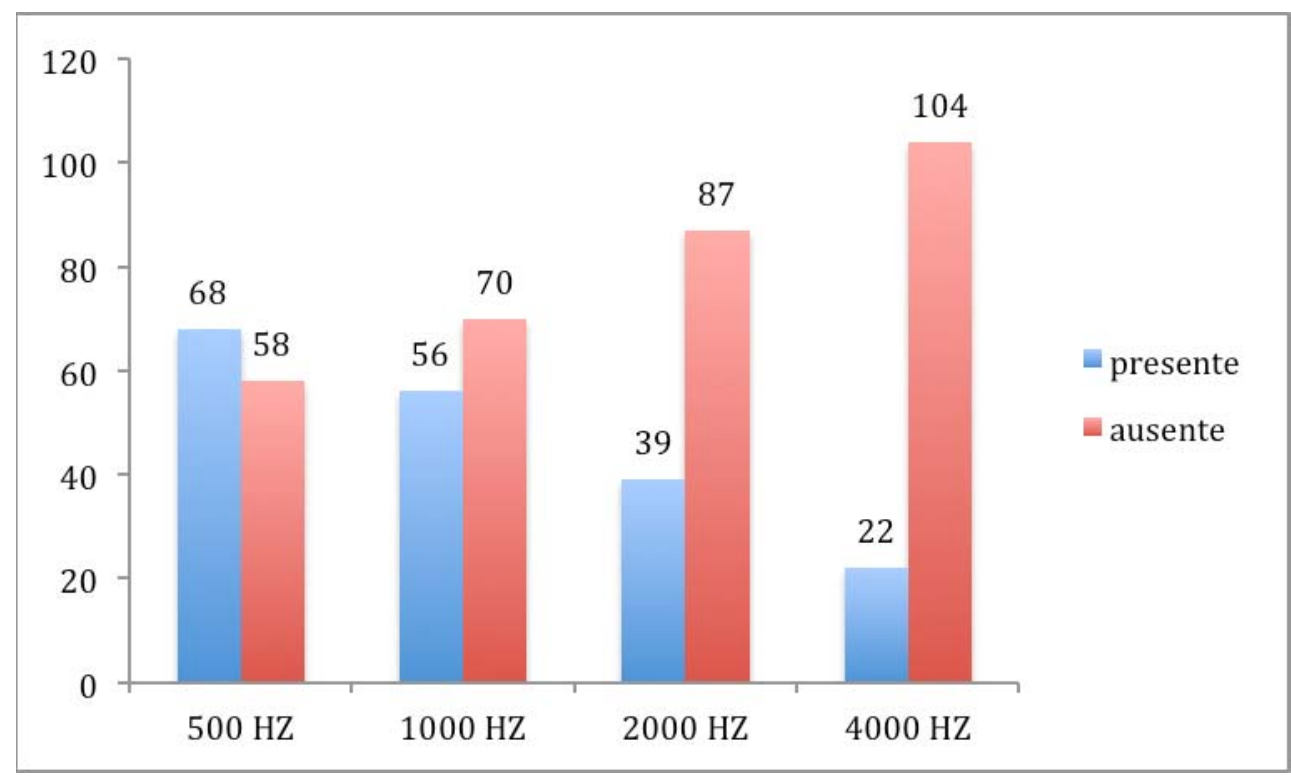

Gráfico 1 - Distribuição dos limiares e respostas ausentes à avaliação comportamental (VRA) nas frequências de 500, 1000, 2000 e $4000 \mathrm{~Hz}$ 


\subsection{RESPOSTAS OBTIDAS À RESPOSTA AUDITIVA DE ESTADO ESTÁVEL}

Foram aferidas 504 medidas entre as 63 crianças, ou seja, 4 frequências em cada uma das 126 orelhas. Foram obtidos 53 limiares à RAEE, o que corresponde a $10,5 \%$ do total.

A distribuição das respostas à RAEE foi similar ao observado na avaliação comportamental, houve predomínio das respostas em $500 \mathrm{~Hz}$. Não houve diferença significativa entre as orelhas direita e esquerda (Gráfico 2).

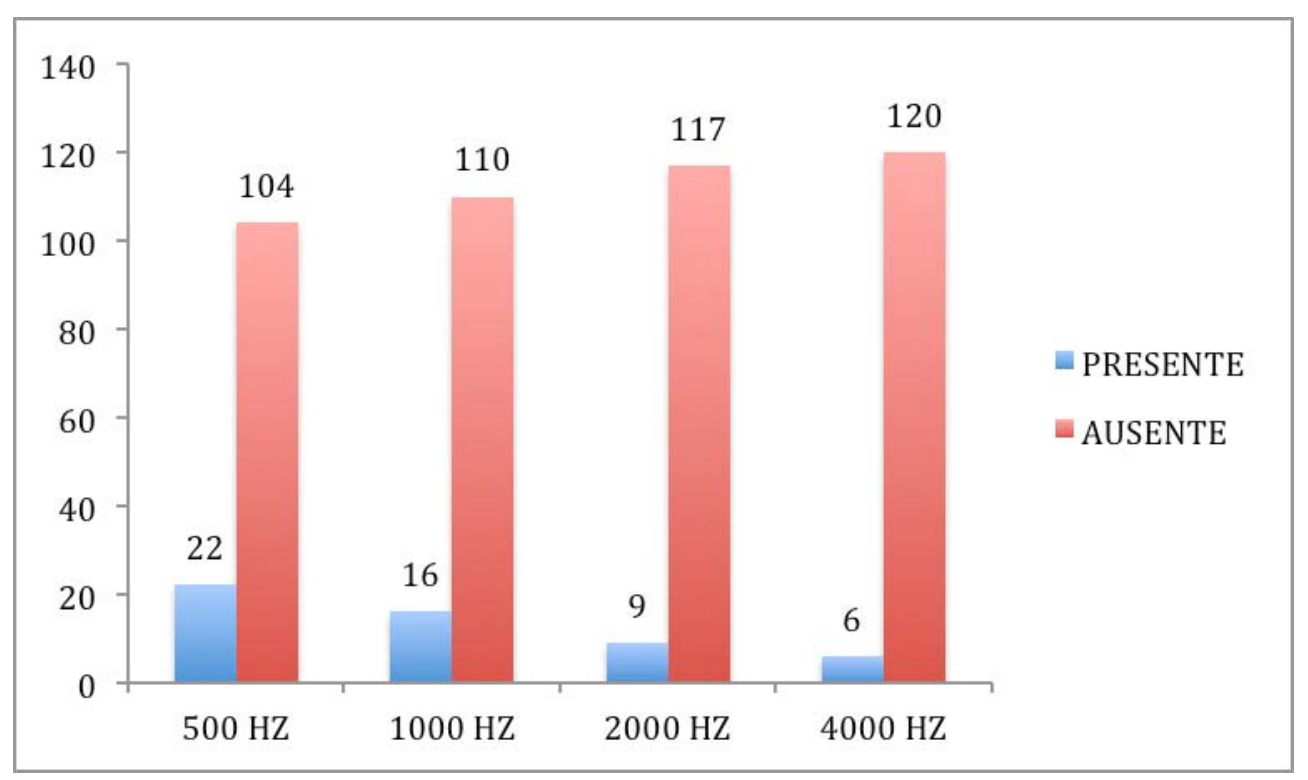

Gráfico 2 - Distribuição dos limiares e respostas ausentes à RAEE, nas frequências de 500, 1000, 2000 e $4000 \mathrm{~Hz}$.

$\mathrm{Na}$ frequência de $500 \mathrm{~Hz}$, foram obtidos 22 respostas, 16 em $1000 \mathrm{~Hz}, 9$ em $2000 \mathrm{~Hz}$ e 6 em $4000 \mathrm{~Hz}$. 


\subsection{COMPARAÇÃO ENTRE LIMIARES À RAEE E NA AVALIAÇÃO POR AUDIOMETRIA COM REFORÇO VISUAL}

As médias e desvio-padrão dos limiares mensuráveis obtidos à VRA e RAEE podem ser observados na tabela 1 . A diferença das médias variou entre 0,09 e 8,94 dB. Não houve diferença estatística em nenhuma frequência testada (tabela 2).

Tabela 1 - Média, desvio-padrão e diferença das médias nas frequências de 500, 1000,2000 e $4000 \mathrm{~Hz}$, na comparação entre VRA e RAEE

\begin{tabular}{|c|c|c|c|c|c|}
\hline & $\begin{array}{l}\text { Limiares } \\
\text { Comnortamentais }\end{array}$ & & Limiares RAEE & & \\
\hline $\begin{array}{l}\text { Frequência } \\
(\mathrm{Hz})\end{array}$ & $\begin{array}{l}\text { Média } \pm d p \\
(d B N A)\end{array}$ & $\mathrm{N}$ (orelhas) & $\begin{array}{l}\text { Média }+\mathrm{dp} \\
(\mathrm{dB} N \mathrm{NA})\end{array}$ & $\mathrm{N}$ (orelhas) & $\begin{array}{l}\text { Diferença } \\
\text { das médias }\end{array}$ \\
\hline 500 & 92,42 & 68 & 101,36 & 22 & $-8,94$ \\
\hline 1000 & 96,69 & 56 & 101,87 & 16 & $-5,18$ \\
\hline 2000 & 101,02 & 39 & 101,11 & 9 & $-0,09$ \\
\hline 4000 & 96,13 & 22 & 100 & 6 & $-3,87$ \\
\hline
\end{tabular}

Nas 126 orelhas avaliadas, foram realizadas 27 comparações entre limiares comportamentais e à RAEE: 12 em $500 \mathrm{~Hz}, 9$ em $1000 \mathrm{~Hz}, 5$ em $2000 \mathrm{~Hz}$ e $1 \mathrm{em}$ $4000 \mathrm{~Hz}$. A ausência de respostas foi analisada separadamente.

Os limiares à RAEE foram obtidos próximo dos limiares comportamentais. A diferença máxima foi de $15 \mathrm{~dB}$. Em 38,9\% das frequências testadas, os limiares subjetivos foram maior ou igual a $100 \mathrm{~dB}$ NA, e em 9\%, maior que $110 \mathrm{~dB}$ NA. 
$\mathrm{Na}$ frequência de $500 \mathrm{~Hz}, 9,5 \%(12 / 126)$ das orelhas apresentaram respostas tanto na VRA quanto na RAEE e 38,1\% (48/126) não apresentaram respostas em ambos os testes. Apresentaram ausência de respostas à RAEE e presença de limiares à VRA 66 orelhas $(52,3 \%)$. Destas, 42 orelhas tinham resposta em intensidade superior a 90 dB NA (Gráfico 3).

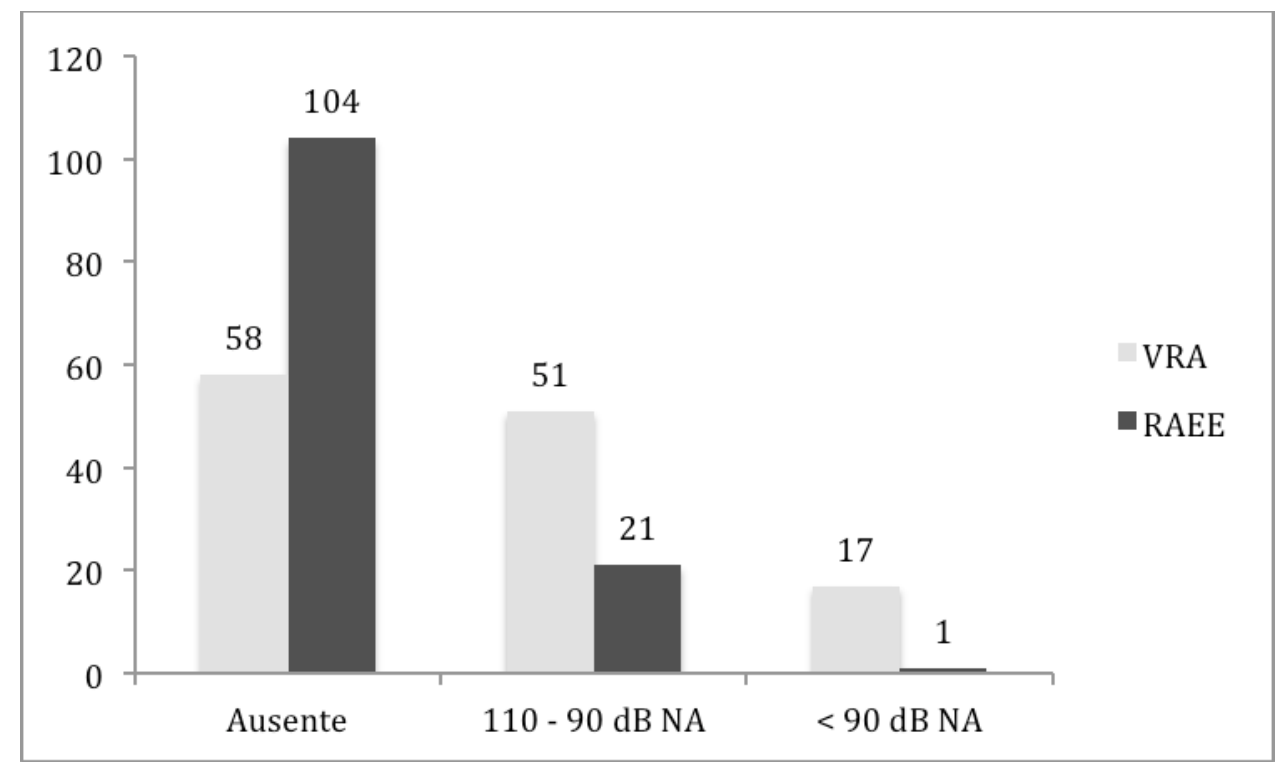

Gráfico 3 - Respostas por categoria em cada método na frequência de $500 \mathrm{~Hz}$. Foram divididas se resposta ausente, limiar entre 90 e $110 \mathrm{~dB}$ ou $<90$ $\mathrm{dB}$ 
$\mathrm{Na}$ frequência de $1000 \mathrm{~Hz}, 7,1 \%$ (9/126) das orelhas apresentaram presença de respostas em ambos os testes e 52,4\% ausência de respostas. Sete orelhas (5,6\%) demonstraram presença de RAEE, apesar de ausência na avaliação subjetiva. Quarenta e quatro orelhas $(34,9 \%)$ apresentaram limiar à VRA e ausência na RAEE, sendo $27,8 \%$ em intensidade superior a 90 dB NA (Gráfico 4).

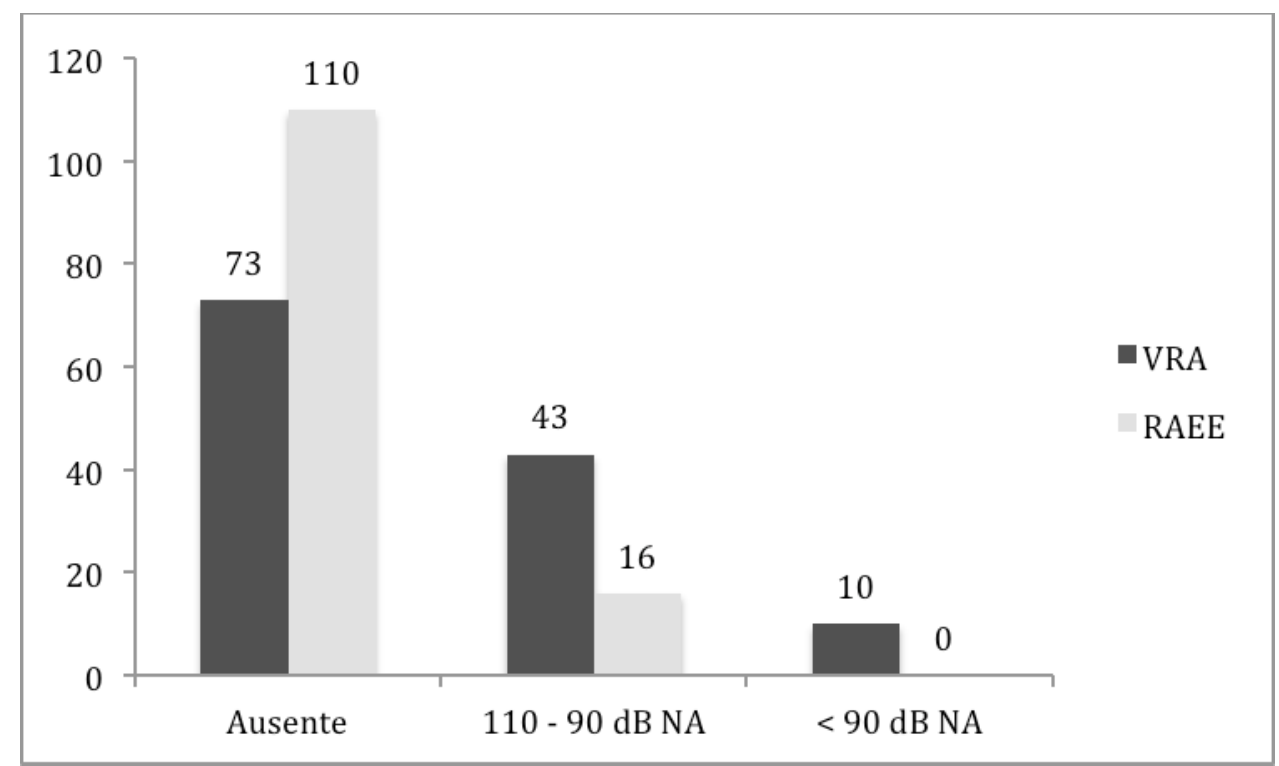

Gráfico 4 - Respostas por categoria em cada método na frequência de $1000 \mathrm{~Hz}$. Foram divididas se resposta ausente, limiar entre 90 e $110 \mathrm{~dB}$ ou $<90$ $\mathrm{dB}$ 
Entre as 126 orelhas testadas em $2000 \mathrm{~Hz}, 5$ respostas foram observadas em ambos os testes (4\%). Noventa e quatro orelhas (74,6\%) apresentaram ausência de respostas em ambos os testes. Vinte e três respostas foram obtidas na VRA com ausência à RAEE (18,3\%), sendo que em 14,3\% em intensidades superiores a $90 \mathrm{~dB}$ NA (Gráfico 5).

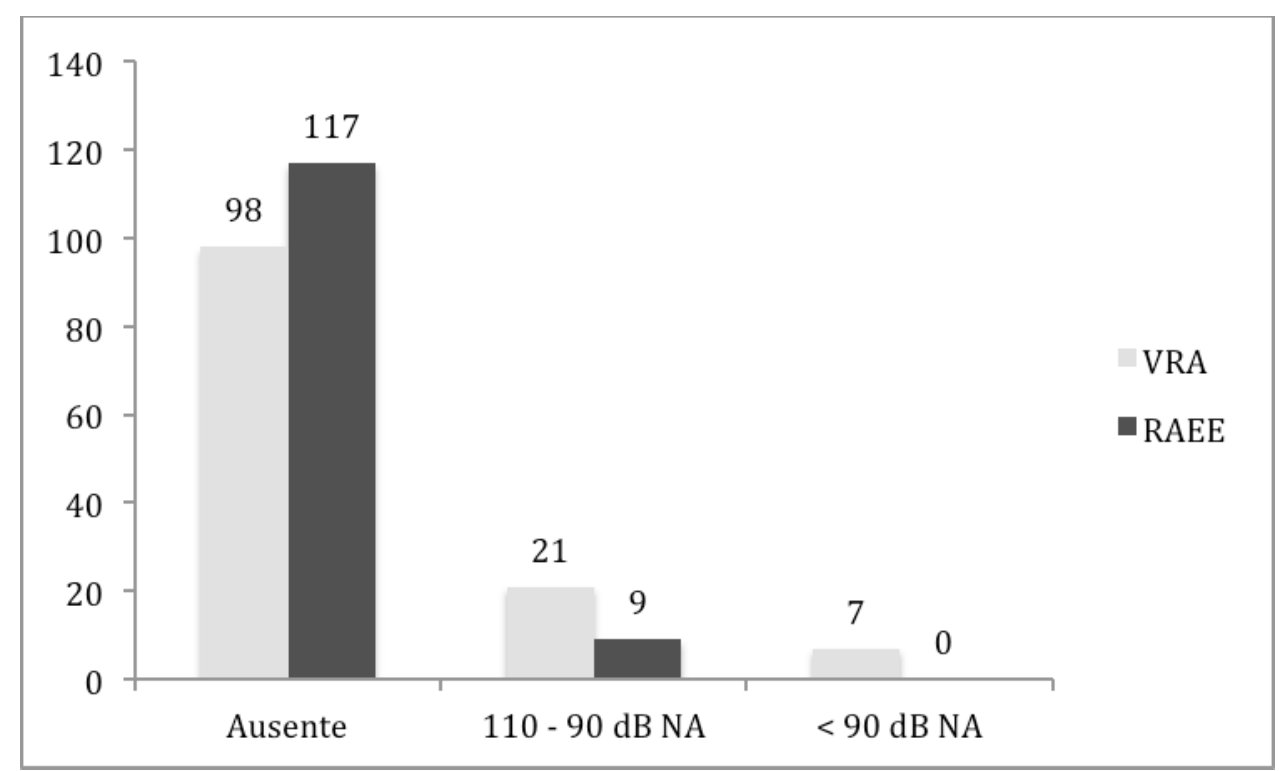

Gráfico 5 - Respostas por categoria em cada método na frequência de $2000 \mathrm{~Hz}$. Foram divididas se resposta ausente, limiar entre 90 e $110 \mathrm{~dB}$ ou $<90$ $\mathrm{dB}$ 
$\mathrm{Na}$ frequência de $4000 \mathrm{~Hz}$ houve apenas 1 resposta em ambos os testes. Oitenta e um porcento (102/126) das medidas apresentaram ausência de respostas em ambos os testes e 18 orelhas apresentaram respostas à VRA, apesar de RAEE ausente. Destes, 11/126 (8,7\%) tinham limiar igual ou superior a 90 dB NA (Gráfico $6)$.

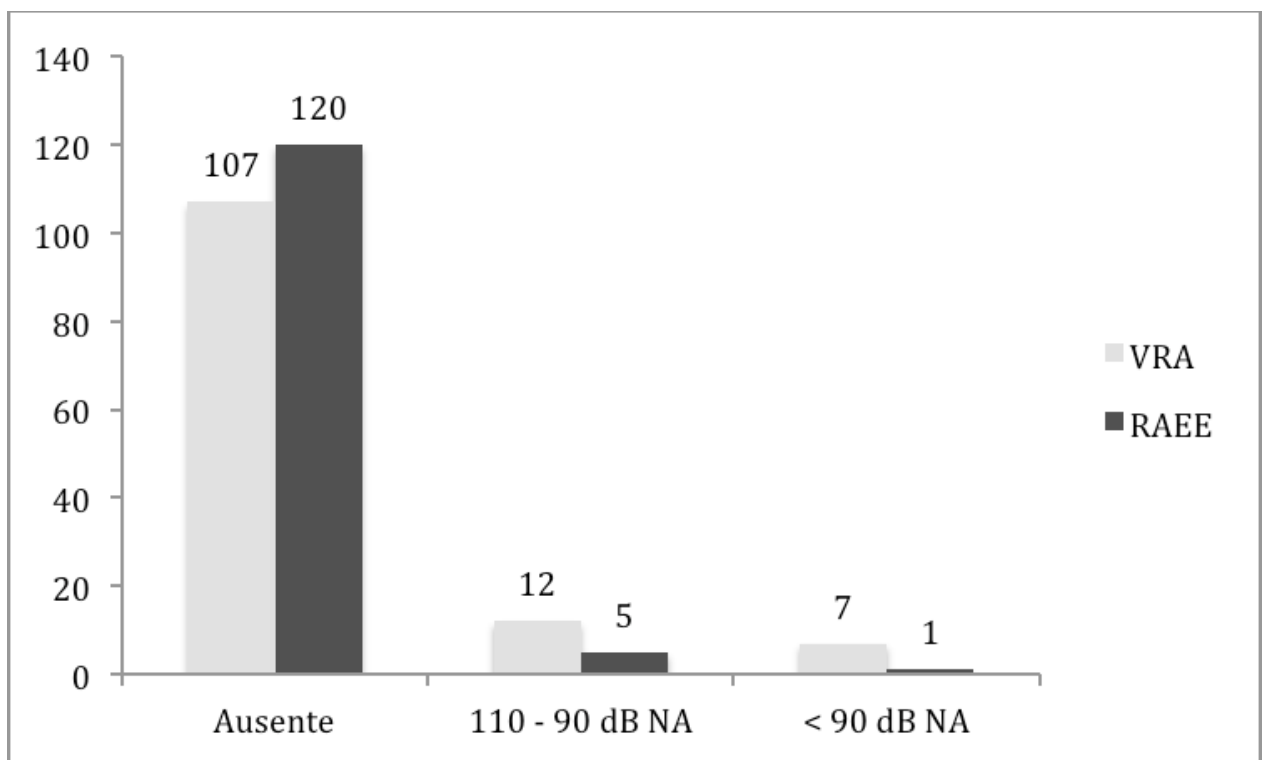

Gráfico 6 - Respostas por categoria em cada método na frequência de $4000 \mathrm{~Hz}$. Foram divididas se resposta ausente, limiar entre 90 e $110 \mathrm{~dB}$ ou $<90$ $\mathrm{dB}$

A tabela 2 mostra que não houve concordância entre RAEE e VRA em todas as frequências avaliadas, com valores de Kappa próximos de 0. Portanto, a sensibilidade da RAEE em identificar intensidades audíveis em comparação à VRA foi baixa $(<20 \%)$. 
Tabela 2 - Comparação entre VRA e RAEE. Divisão dos limiares obtidos em faixa de intensidades de acordo com o grau de perda Utilizado teste Kappa ponderado para estatística. Nas colunas da direita, observa-se medidas de sensibilidade e especificidade para cada uma das 4 frequências testadas

\begin{tabular}{|c|c|c|c|c|c|c|c|c|c|c|c|c|}
\hline \multirow{3}{*}{ Frequência } & \multicolumn{9}{|c|}{ Avaliação Comportamental } & \multirow{3}{*}{$\begin{array}{c}\text { Kappa Ponderado } \\
\text { (IC 95\%) }\end{array}$} & \multirow{3}{*}{$\begin{array}{c}\text { Sensibilidade } \\
\%\end{array}$} & \multirow{3}{*}{$\begin{array}{c}\text { Especificidade } \\
\%\end{array}$} \\
\hline & \multirow[t]{2}{*}{ RAEE } & \multicolumn{2}{|c|}{ Ausente } & \multicolumn{2}{|c|}{$110 \mathrm{~dB}-90 \mathrm{~dB}$} & \multicolumn{2}{|c|}{$<90 \mathrm{~dB}$} & \multicolumn{2}{|c|}{ Total } & & & \\
\hline & & $\mathrm{N}$ & $\%$ & $\mathrm{~N}$ & $\%$ & $\mathrm{~N}$ & $\%$ & $\mathrm{~N}$ & $\%$ & & & \\
\hline \multirow{4}{*}{$500 \mathrm{~Hz}$} & Ausente & 48 & 38,1 & 42 & 33,3 & 14 & 11,1 & 104 & 82,5 & \multirow{4}{*}{$\begin{array}{c}0,000 \\
(-0,101 ; 0,100)\end{array}$} & \multirow{4}{*}{17,6} & \multirow{4}{*}{82,8} \\
\hline & $110 \mathrm{~dB}-90 \mathrm{~dB}$ & 9 & 7,1 & 9 & 7,1 & 3 & 2,4 & 21 & 16,7 & & & \\
\hline & $<90 \mathrm{~dB}$ & 1 & 0,8 & 0 & 0,0 & 0 & 0,0 & 1 & 0,8 & & & \\
\hline & Total & 58 & 46,0 & 51 & 40,5 & 17 & 13,5 & 126 & 100,0 & & & \\
\hline \multirow{4}{*}{$1000 \mathrm{~Hz}$} & Ausente & 66 & 52,4 & 35 & 27,8 & 9 & 7,1 & 110 & 87,3 & \multirow{4}{*}{$\begin{array}{c}0,082 \\
(-0,053 ; 0,216)\end{array}$} & \multirow{4}{*}{17,0} & \multirow{4}{*}{90,4} \\
\hline & $110 \mathrm{~dB}-90 \mathrm{~dB}$ & 7 & 5,6 & 8 & 6,3 & 1 & 0,8 & 16 & 12,7 & & & \\
\hline & $<90 \mathrm{~dB}$ & 0 & 0,0 & 0 & 0,0 & 0 & 0,0 & 0 & 0,0 & & & \\
\hline & Total & 73 & 57,9 & 43 & 34,1 & 10 & 7,9 & 126 & 100,0 & & & \\
\hline \multirow{4}{*}{$2000 \mathrm{~Hz}$} & Ausente & 94 & 74,6 & 18 & 14,3 & 5 & 4,0 & 117 & 92,9 & \multirow{4}{*}{$\begin{array}{c}0,182 \\
(-0,005 ; 0,368)\end{array}$} & \multirow{4}{*}{17,9} & \multirow{4}{*}{95,9} \\
\hline & $110 \mathrm{~dB}-90 \mathrm{~dB}$ & 4 & 3,2 & 3 & 2,4 & 2 & 1,6 & 9 & 7,1 & & & \\
\hline & $<90 \mathrm{~dB}$ & 0 & 0,0 & 0 & 0,0 & 0 & 0,0 & 0 & 0,0 & & & \\
\hline & Total & 98 & 77,8 & 21 & 16,7 & 7 & 5,6 & 126 & 100,0 & & & \\
\hline \multirow{4}{*}{$4000 \mathrm{~Hz}$} & Ausente & 102 & 81,0 & 11 & 8,7 & 7 & 5,6 & 120 & 95,2 & & \multirow{4}{*}{5,3} & \multirow{4}{*}{95,3} \\
\hline & $110 \mathrm{~dB}-90 \mathrm{~dB}$ & 5 & 4,0 & 0 & 0,0 & 0 & 0,0 & 5 & 4,0 & 0,003 & & \\
\hline & $<90 \mathrm{~dB}$ & 0 & 0,0 & 1 & 0,8 & 0 & 0,0 & 1 & 0,8 & $(-0,104 ; 0,109)$ & & \\
\hline & Total & 107 & 84,9 & 12 & 9,5 & 7 & 5,6 & 126 & 100,0 & & & \\
\hline
\end{tabular}


A sensibilidade e especificidade foram calculadas considerando a VRA como padrão-ouro para detecção de audição residual. Principalmente em 1000, 2000 e $4000 \mathrm{~Hz}$, a especificidade foi maior que 90 \% (tabela 2). Na frequência de $500 \mathrm{~Hz}$, a especificidade foi de 82,8\%, 90,4\% em $1000 \mathrm{~Hz}, 95,9 \%$ em $2000 \mathrm{~Hz}$ e 95,3\% em $4000 \mathrm{~Hz}$.

Nas orelhas com ausência de respostas comportamentais em 120 dB NA, todos os limiares às RAEE foram medidos na faixa de perda auditiva profunda. Entre eles, mais de $90 \%$ eram $\geq 110 \mathrm{~dB}$ NA. 
DISCUSSÃO 
A ausência de respostas em altas intensidades à RAEE foi o principal achado deste estudo. Entre as frequências testadas, $89 \%$ não apresentaram nenhuma resposta em 110 dB NA. A alta especificidade das RAEE em 1000, 2000 e $4000 \mathrm{~Hz}$, quando comparada à avaliação comportamental demonstra que a ausência de respostas à RAEE é um forte indicador de perda auditiva profunda, o que pode auxiliar na decisão pelo implante coclear.

Esses resultados são consistentes com os achados de Rance et al., $1998^{[15]}$ que mostraram que a ausência de respostas à RAEE, no limite máximo de estimulação, é indicador confiável de surdez profunda. Em 42 das 126 orelhas testadas, não foram obtidas respostas em ambos os testes. Além das 42 com ausência de respostas, em 31 orelhas os limiares à VRA estiveram na faixa de surdez profunda.

De acordo com Swanepoel et al., 2004 ${ }^{[78]}$ a RAEE pode auxiliar nos candidatos ao implante coclear ou crianças difíceis de serem testadas, cujos testes audiológicos não forem elucidativos ou não puderem ser realizados.

Swanepoel e Hugo, $2004^{[14]}$ estudaram crianças entre 10 e 60 meses de idade (média de 29 meses), com suspeita de surdez severo-profunda. Observaram que 87\% dos limiares à RAEE foram maior ou igual a $100 \mathrm{~dB}$ NA e $47 \%$ em intensidades superiores a $115 \mathrm{~dB}$ NA. A menor quantidade de respostas foi obtida na frequência de $500 \mathrm{~Hz}$.

Os resultados do presente estudo diferem dos supra-citados, já que limitamos a intensidade máxima de estimulação em $110 \mathrm{~dB}$ NA para todas as frequências. Como todas as avaliações foram realizadas sem o prévio conhecimento dos limiares comportamentais, optou-se por não utilizar intensidades maiores para evitar dano coclear. O único dado audiológico conhecido previamente, era a ausência de respostas ao PEATE aos cliques em $90 \mathrm{~dB}$ NA, o que não possibilita a diferenciação entre surdez severa e profunda e, ainda, pode estar associada ao atraso da maturação das vias auditivas ascendentes, principalmente em crianças prematuras. Também, 
houve a preocupação em relação à possibilidade de respostas artefatuais em intensidades maiores que $110 \mathrm{~dB}$ NA, como já descrito em estudos anteriores ${ }^{[83-85]}$.

De acordo com Swanepoel et al., $2004^{[14]}$ o uso de fones de inserção pode minimizar a possibilidade de respostas somatossensoriais em altas intensidades, por isso optamos por utilizá-los em todos os testes.

Ao contrário do estudo de Swanepoel e Hugo, $2004^{[14]}$ que obtiveram limiares para apenas um indivíduo, neste estudo, 41 crianças apresentaram respostas em pelo menos uma frequência na avaliação comportamental. Alguns deles tiveram que ser avaliados em mais de uma sessão para obter resultados confiáveis. Para a avaliação subjetiva, foi usado $120 \mathrm{~dB}$ NA como limite máximo de estimulação, com pesquisa descendente de $10 \mathrm{~dB}$. Isso pode explicar o motivo pelo qual foram obtidas mais respostas comportamentais que à RAEE. Na avaliação comportamental obtevese maior número de respostas, pois a estimulação inclui intensidades de até $120 \mathrm{~dB}$ NA, superiores ao utilizado na RAEE. Como a criança estava acordada, esta poderia manifestar-se em caso de desconforto com a intensidade do estímulo.

Desde 2004, poucos foram os estudos que utilizaram a RAEE em crianças com perda auditiva severa a profunda exclusivamente.

Kandongan e Dalgic, $2013^{[104]}$ avaliaram 20 crianças através de PEATE e RAEE. Observaram limiares mensuráveis à RAEE em 33 das 40 orelhas testadas, com ausência de respostas ao PEATE e esta informação pode ser utilizada para avaliação de amplificação sonora confiável.

Ramos et al., $2015^{[88]}$ obtiveram 202/320 (63,1\%) limiares, utilizando-se estimulação à RAEE de até 120 dB NA em 40 indivíduos com perda auditiva severoprofunda. No entanto, foram testados adolescentes e adultos que podiam se manifestar se a intensidade do estímulo fosse muito alta. Neste estudo, a RAEE demonstrou alta sensibilidade $(96 \%)$ e especificidade $(91,6 \%)$, quando comparada à audiometria tonal.

No presente estudo, a sensibilidade foi baixa para todas as frequências quando comparado à avaliação comportamental. Em $500 \mathrm{~Hz}$ foi de 17,6\%, 17\% em $1000 \mathrm{~Hz}, 17,9 \%$ em $2000 \mathrm{~Hz}$ e 5,3\% em $4000 \mathrm{~Hz}$. Não houve correlação entre os métodos, devido ao pequeno número de respostas à $\operatorname{RAEE~}(\mathrm{p}>0,05)$. Como a maioria 
dos pacientes estava na faixa de surdez profunda, poucas respostas à RAEE foram utilizadas para esta análise (53/504).

Como a ausência de respostas às RAEE é um forte preditor de ausência de audição residual ${ }^{[69]}$, podemos considerar que os pacientes avaliados neste estudo são potenciais candidatos ao implante coclear. Rance e Briggs, $2002{ }^{[69]}$ já haviam demonstrado que na ausência de limiares à RAEE, os limiares subjetivos eram igual ou superior a 115 dB NA em 93,4\% dos avaliados. Ainda, Ramos et al., $2015^{[88]}$ observaram que em 93,2\% dos casos em que não houve respostas à RAEE, também não havia respostas na audiometria tonal. Tal informação é mais importante antes do implante coclear que a ausência de respostas ao PEATE clique, que não exclui a possibilidade de audição residual ${ }^{[82]}$.

Todas as crianças devem utilizar aparelho de amplificação sonora individual (AASI) antes do implante coclear, mas na ausência de respostas à RAEE, a família poderia ser orientada que o aproveitamento auditivo pode não ser adequado. Ao mesmo tempo, na presença de limiares à RAEE e ausência de respostas ao PEATE, a criança apresenta audição residual em níveis para amplificação, mas não prediz que a amplificação seja eficaz e garanta a aquisição de linguagem ${ }^{[14,69]}$. Nesses casos, os limiares da RAEE podem ser utilizados para a adaptação adequada do AASI.

A comparação entre os limiares da RAEE e avaliação comportamental tem forte correlação em sujeitos com perda auditiva. A diferença entre os limiares à RAEE e tonal diminui conforme piora a perda auditiva ${ }^{[58,64,82]}$. Portanto, quando há limiar à RAEE, ela fornece importantes informações para protetização em crianças pequenas quando os testes comportamentais são inconclusivos e para a escolha da orelha do implante coclear, se a opção for por implante unilateral.

Apesar de alguns pesquisadores levantarem a possibilidade de respostas artefatuais em estimulação com altas intensidades em $2004^{[83-85]}$, poucos estudos foram conduzidos utilizando-se da RAEE na investigação de audição residual em candidatos ao implante coclear. Semelhante ao presente estudo, Beck et al. 2011 e

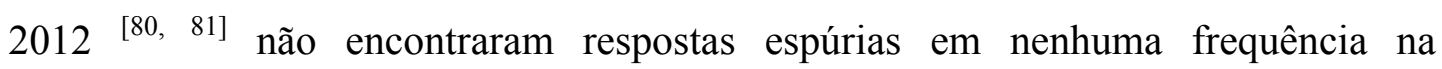
intensidade máxima de estimulação de 110 dB NA. Os autores utilizaram taxas de conversão analógico-digital de $1200 \mathrm{~Hz}$ e seleção de taxas para as quais as 
frequências portadoras não fossem um múltiplo inteiro, conforme proposto por Small e Stapells, $2004{ }^{[84]}$ e Picton e John, $2004{ }^{[83]}$. Usando a mesma taxa de conversão em intensidades de até $120 \mathrm{~dB}$ NA, Ramos et al. $2015^{\left[{ }^{[8]} \text { observaram que os limiares à }\right.}$ RAEE na ausência de respostas tonais foram raros na sua população de estudo, correspondendo a 3,1\% das frequências testadas, menos que o esperado estatisticamente ao acaso ${ }^{[105]}$.

No presente estudo, existem alguns fatores que podem contribuir para a pequena quantidade de respostas à RAEE e a baixa sensibilidade. Em primeiro lugar, limitamos a intensidade máxima em $110 \mathrm{~dB}$ NA, portanto menos respostas são esperadas em comparação a outros autores que utilizaram intensidades mais elevadas. Considerando-se que limiares à RAEE na perda auditiva sensório-neural são entre 6 e 11 dB mais elevados que ao PEATE em crianças, limiares à RAEE em $110 \mathrm{~dB}$ NA devem indicar limiar tonal presumido melhor ou igual a $100 \mathrm{~dB} \mathrm{NA}^{[106]}$. A avaliação comportamental detectou 89/504 respostas em intensidades igual ou superior a $110 \mathrm{~dB}$ NA, que não poderiam ser observadas com o estímulo da RAEE limitado a 110 dB NA. Apesar desta estratégia ter limitado a pesquisa de respostas, consideramos que esta evitaria dano coclear. Todo cuidado deve ser tomado na estimulação da RAEE em altas intensidades, especialmente em crianças sem avaliação comportamental prévia, prematuros e nos casos de doença do espectro da neuropatia auditiva. Convém ainda ressaltar que o método pode ser inadequado em pacientes com hipofunção ou agenesia do nervo coclear e malformação da orelha interna.

A amplitude da RAEE é pequena próximo ao limiar, por isso algumas respostas podem ter sido perdidas, devido à relação sinal-ruído insuficiente. O nível de ruído depende da amplitude do EEG e do tempo de exame, geralmente diminuindo durante o teste. Nas intensidades maiores que $100 \mathrm{~dB}$ NA, não são utilizadas mais de 10 varreduras em cada intensidade. Cada varredura contém 16 segmentos de 1,024 segundos, portanto o tempo de exame é de aproximadamente 163 segundos para cada frequência, ou seja, menos de 3 minutos. Considerando-se pequenas amplitudes próximas do limiar, pode ser difícil de se obter respostas com relação sinal-ruído significativa com apenas 10 varreduras. O uso do estímulo 
CHIRP, com maior tempo de gravação deve produzir respostas com melhor relação sinal-ruído e amplitude ${ }^{[107]}$.

É sabido que o estado de alerta do indivíduo contribui para o nível de ruído e interfere na detecção das respostas. No Hospital das Clínicas da FMUSP, os exames são realizados com anestesia geral inalatória (Sevoflurane), que permite suavização do EEG e ajuda a atingir nível de ruído aceitável, mesmo em altas intensidades.

Estudos prévios em adultos, mostraram que a amplitude da RAEE em $80 \mathrm{~Hz}$ deve ser até 5 vezes menor que a resposta de $40 \mathrm{~Hz}$. Tal dado foi confirmado por Tlumak et al., $2012^{[108]}$ que encontraram amplitudes menores na estimulação com 80 $\mathrm{Hz}$ em comparação a de $40 \mathrm{~Hz}$ em crianças. No entanto, eventualmente, 10 varreduras não seriam o suficiente para observar-se redução do nível de ruído em nível inferior a $30 \mathrm{nV}$. Uma contribuição seria extender as gravações para 12 varreduras nestes casos. Poderia-se ainda, tentar a estimulação com taxa de $40 \mathrm{~Hz}$ conforme sugerido por Muhler et al., $2014^{[109]}$. Até o presente momento não existem dados à respeito do uso do CHIRP em intensidades superiores a $80 \mathrm{~dB}$ NA para a RAEE.

A casuística deste estudo é uma das maiores da literatura desde Rance et al., $1998^{[15]}$ com crianças portadoras de surdez severo-profunda. A limitação, no entanto, foi a quantidade reduzida de respostas obtidas à RAEE. Isso se deve justamente à característica da população estudada com a maioria dos limiares na faixa de surdez profunda, onde as respostas à RAEE não são esperadas. A ausência à RAEE é um dado relevante para as equipes de implante coclear e as famílias do pequeno paciente, proporcionando maior segurança na indicação cirúrgica.

Ainda, como seguimento deste estudo, poderia ser interessante avaliar as respostas ao implante coclear das crianças que apresentaram audição residual antes da cirurgia. 
CONCLUSÃO 


\section{CONCLUSÃO}

O principal achado deste estudo foi a ausência de respostas à RAEE em $61,5 \%$ das orelhas testadas.

Do total de medidas efetuadas à RAEE, $99,6 \%$ se encontraram na faixa de surdez profunda.

Na VRA, 91,9\% das medidas efetuadas se encontraram na faixa de surdez profunda.

A especificidade foi superior a 90\% nas frequências de 1000, 2000 e $4000 \mathrm{~Hz}$ e em $500 \mathrm{~Hz}$ de $82,8 \%$.

Pela característica da amostra, o número reduzido de respostas à RAEE não permitiu correlacionar os limiares entre os métodos. 
ANEXOS 


\section{Anexo A - CAPPesq}

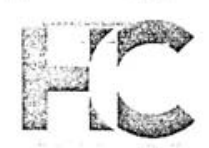

Hospital das Clínicas da FMUSP

Comissão de Ética para Análise de Projetos de Pesquisa - CAPPesq

\section{PROJETO DE PESQUISA}

Título: ESTUDO COMPARATIVO ENTRE RESPOSTAS AUDITIVAS DE ESTADO ESTÁVEL E AVALIAÇÃO SUBJETIVA NA INFÂNCIA

Pesquisador Responsável: Prof. Dr. Rubens Vuono de Brito Versão: 1

Neto

Pesquisador Executante: Roberto Miquelino de Oliveira $\quad$ CAAE: 00963812.5.0000.0068 Beck

Finalidade Acadêmica Doutorado

Instituição: HC-FMUSP

Departamento: OFTALMOLOGIA E OTORRINOLARINGOLOGIA

\section{PARECER CONSUBSTANCIADO DO CEP}

Número do Parecer: 38954

Data da Relatoria: 20/06/12

Apresentação do Projeto:

Trata-se de projeto de doutorado que visa a estudar as respostas auditivas de estado estável em pacientes com perda auditiva neurossensorial severa ou profunda, candidatos ao implante coclear. A perda auditiva não identificada na infância pode ocasionar prejuizos nas habilidades da fala e linguagem ao longo da vida, com grande impacto sobre a comunicação, cognição, desempenho escolar, desenvolvimento emocional e bem-estar psicossocial. Mesmo crianças com perdas auditivas leves ou unilaterais podem apresentar menor desempenho acadêmico. A detecção precoce e intervenção dentro do período crítico para desenvolvimento da fala, linguagem e cognição melhoram o desempenho individual, independente da magnitude da perda auditiva.

Objetivo da Pesquisa:

O estudo busca correlacionar o nível dos limiares eletrofisiológicos obtidos nas respostas auditivas de estado estável aos limiares obtidos na avaliação subjetiva comportamental nas frequências de $500,1000,2000$ e $4000 \mathrm{~Hz}$, em crianças de seis meses a quatro anos de idade.

Avaliação dos Riscos e Benefícios:

Estudo de risco minimo, envolvendo a aplicação de teste de potencial auditivo de estado estável que será realizado sob anestesia. Este protocolo segue o procedimento padrão adotado pelo grupo de eletrofisiologia do HC-FMUSP, para realização dos exames em todas as crianças avaliadas neste setor.

Comentários e Considerações sobre a Pesquisa:

Justifica-se a condução do estudo em vista da importância do diagnóstico precoce para o sucesso da intervenção em crianças com perda auditiva severa ou profunda. Neste caso, a obtenção de limiares auditivos separadamente para cada orelha por procedimentos

Rua Dr. Ovídio Pires de Campos, 225 - Prédio da Administração - 5 andar

CEP 05403-010 - São Paulo - SP.

5511 2661-6442 ramais: 16, 17, 18 e 20 | cappesq@hcnet.usp.br 
Anexos 54

\section{Hospital das Clínicas da FMUSP}

Comissão de Ética para Análise de Projetos de Pesquisa - CAPPesq

eletrofisiológicos torna-se imperativo, principalmente para a tomada de decisão sobre uso de amplificação ou de implante coclear.

Considerações sobre os Termos de apresentação obrigatória:

O Termo de Consentimento Livre e Esclarecido contém as informações necessárias,

apresentadas de forma clara e com linguagem acessivel à população alvo.

Recomendações:

Fazer uma revisão gramatical no projeto que contém inadequações no uso do tempo verbal em diversos parágrafos do texto, principalmente no capítulo "Materiais e Métodos".

Conclusões ou Pendências e Lista de Inadequações:

Parecer favorável à aprovação.

Situação do Parecer:

Aprovado

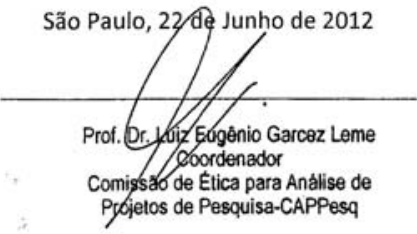

Rua Dr. Ovídio Pires de Campos, 225 - Prédio da Administração - 5ำ andar CEP 05403-010 - São Paulo - SP.

5511 2661-6442 ramais: 16, 17, 18 e 20 | cappesq@hcnet.usp.br 
Anexos 55

\title{
Anexo B - Plataforma Brasil
}

\author{
Plataforma Brasil - Ministério da Saúde
}

Hospital das Clinicas da Faculdade de Medicina da USP - HCFMUSP

PROJETO DE PESQUISA

\begin{tabular}{|c|c|c|}
\hline $\begin{array}{l}\text { Titulo: ESTUDO COMPARATIVO ENTRE RESPOSTAS } \\
\text { AVALIAÇÃO SUBJETIVA NA INFÂNCIA }\end{array}$ & AUDITIV & AS DE ESTADO ESTÁVEL E \\
\hline Pesquisador: rubens vuono de brito neto & Versão: & 1 \\
\hline $\begin{array}{l}\text { Instituição: Hospital das Clinicas da Faculdade de Medicina } \\
\text { da USP }\end{array}$ & CAAE: & 00963812.5 .0000 .0068 \\
\hline
\end{tabular}

\section{PARECER CONSUBSTANCIADO DO CEP}

\author{
Número do Parecer: 41225 \\ Data da Relatoria:20/06/2012
}

Apresentação do Projeto:

Trata-se de projeto de doutorado que visa a estudar as respostas auditivas de estado estável em pacientes com perda auditiva neurossensorial severa ou profunda, candidatos ao implante coclear. A perda auditiva não identificada na infância pode ocasionar prejuizos nas habilidades da fala e linguagem ao longo da vida, com grande impacto sobre a comunicação, cognição, desempenho escolar, desenvolvimento emocional e bem-estar psicossocial. Mesmo crianças com perdas auditivas leves ou unilaterais podem apresentar menor desempenho acadêmico. A detecção precoce e intervenção dentro do periodo critico para desenvolvimento da fala, linguagem e cogniçẵo melhoram o desempenho individual, independente da magnitude da perda auditiva.

Objetivo da Pesquisa:

O estudo busca correlacionar o nivel dos limiares eletrofisiológicos obtidos nas respostas auditivas de estado estável aos limiares obtidos na avaliaçăo subjetiva comportamental nas frequências de 500, 1000, 2000 e 4000 $\mathrm{Hz}$, em crianças de seis meses a quatro anos de idade.

Avaliação dos Riscos e Beneficios:

Estudo de risco mínimo, envolvendo a aplicação de teste de potencial auditivo de estado estável que será realizado sob anestesia. Este protocolo segue o procedimento padrăo adotado pelo grupo de eletrofisiologia do HC-FMUSP, para realização dos exames em todas as crianças avaliadas neste setor.

Comentários e Considerações sobre a Pesquisa:

Justifica-se a conduçăo do estudo em vista da importância do diagnóstico precoce para o sucesso da intervençăo em crianças com perda auditiva severa ou profunda. Neste caso, a obtenção de limiares auditivos separadamente para cada orelha por procedimentos eletrofisiológicos torna-se imperativo, principalmente para a tomada de decisão sobre uso de amplificação ou de implante coclear.

Consideraçōes sobre os Termos de apresentação obrigatória:

O Termo de Consentimento Livre e Esclarecido contém as informações necessárias, apresentadas de forma clara e com linguagem acessivel à populaçăo alvo.

Recomendações:

Fazer uma revisăo gramatical no projeto que contém inadequaçōes no uso do tempo verbal em diversos parágrafos do texto, principalmente no capitulo "Materiais e Métodos".

Conclusões ou Pendências e Lista de Inadequações:

Meu parecer é favorável à aprovação.

Situação do Parecer:

Aprovado

Necessita Apreciação da CONEP:

Năo 


\section{Anexo C. Termo de Consentimento Livre e Esclarecido}

HOSPITAL DAS CLÍNICAS DA FACULDADE DE MEDICINA DA UNIVERSIDADE DE SÃO PAULO-HCFMUSP

TERMO DE CONSENTIMENTO LIVRE E ESCLARECIDO

DADOS DE IDENTIFICAÇÃO DO SUJEITO DA PESQUISA OU RESPONSÁVEL LEGAL

1. NOME:

DOCUMENTO DE IDENTIDADE $\mathrm{N}^{\circ}$ : SEXO : .M $\square \quad \mathrm{F} \square$

DATA NASCIMENTO:

ENDEREÇO $\mathrm{N}^{\circ}$ APTO:

BAIRRO: CIDADE

CEP: TELEFONE: DDD ( .).

2.RESPONSÁVEL LEGAL

NATUREZA (grau de parentesco, tutor, curador etc.) DOCUMENTO DE IDENTIDADE : SEXO: $M \square F \square$

DATA NASCIMENTO.

ENDEREÇO: $\mathrm{N}^{\circ}$ APTO:

BAIRRO: CIDADE:

CEP: TELEFONE: (

\section{DADOS SOBRE A PESQUISA}

1. TÍTULO DO PROTOCOLO DE PESQUISA: ESTUDO COMPARATIVO ENTRE RESPOSTAS AUDITIVAS DE ESTADO ESTÁVEL E AVALIAÇÃO SUBJETIVA NA INFÂNCIA

PESQUISADOR : Prof. Dr. Rubens Vuono de Brito Neto

CARGO/FUNÇÃO: Livre Docente INSCRIÇÃO CONSELHO REGIONAL Nº 80.107

UNIDADE DO HCFMUSP: Divisão de Clínica Otorrinolaringológica

3. AVALIAÇÃO DO RISCO DA PESQUISA:

$\begin{array}{ll}\text { RISCO MÍNIMOX } & \text { RISCO MÉDIO } \square \\ \text { RISCO BAIXO } \square & \text { RISCO MAIOR } \square\end{array}$

4.DURAÇÃO DA PESQUISA: 18 meses 


\section{HOSPITAL DAS CLÍNICAS DA FACULDADE DE MEDICINA DA UNIVERSIDADE DE SÃO PAULO-HCFMUSP}

Essas informações estão sendo fornecidas para participação voluntária de seu filho(a) neste estudo, que tem como objetivo a comparação de dois métodos de avaliação auditiva: A audiometria comportamental e o exame de Respostas Auditivas de Estado Estável.

A avaliação comportamental/subjetiva será realizada por fonoaudiólogas designadas do setor de fonoaudiologia do grupo de Implante Coclear do HC-FMUSP utilizando-se de estímulos auditivos (sons) e reforço visual, que serão apresentados em intensidades variáveis para testar a audição da criança.

Para realização do exame de Respostas auditivas de estado estável, serão posicionados eletrodos em 3 pontos (ombro, nuca e testa) após limpeza do local com creme esfoliante. O exame dura cerca de 1 hora e neste período a criança vai estar deitada em uma maca confortável em ambiente silencioso e com fones de ouvido que transmitem sons de intensidades variáveis. O exame será realizada sob anestesia geral inalatória (Sevofluarone) através de máscara, conduzida por anestesista do HCFMUSP. O exame não é invasivo e é realizado para avaliação da audição. O uso da anestesia é procedimento padrão do grupo de eletrofisiologia e seu uso não esta vinculado à pesquisa, e sim ao exame de todas as crianças avaliadas neste setor.

Não são esperados riscos e/ou desconforto durante a realização do procedimento.

O benefício para o paciente é no sentido de esclarecer melhor a avaliação auditiva.

É garantida a liberdade da retirada do consentimento a qulquer momento e deixar de participar do estudo, sem qualquer prejuízo à continuidade de seu tratamento na instituição. As informações obtidas serão analisadas em conjunto com as de outros pacientes, não sendo divulgado a identificação de nenhum paciente.

Não há despesas pessoais para o participante em qualquer fase do estudo, incluindo exames e consultas. Também não há compensação financeira relacionada à sua participação. Se existir qualquer despesa adicional, ela será absorvida pelo orçamento da pesquisa. O pesquisador compromete-se a utilizar os dados e o material coletado somente para esta pesquisa, podendo os mesmos ser utilizados em aulas e apresentações no meio acadêmico médico, como congressos, por exemplo, ou em revista científica da área médica, sempre omitindo a identidade do paciente.

Em qualquer etapa do estudo, você terá acesso aos profissionais responsáveis pela pesquisa para esclarecimento de eventuais dúvidas. O principal investigador é o Prof. Dr. Rubens Vuono de Brito Neto, que pode ser encontrado no endereço: R. Dr. Enéas de Carvalho Aguiar, 255 - Instituto Central do Hospital das Clínicas da FMUSP, $6^{\circ}$ andar sala 6173, Telefone(s) 11- 2661-7183. Se você tiver alguma consideração ou dúvida sobre a ética da pesquisa, entre em contato com o Comitê de Ética 
em Pesquisa (CEP) - Rua Ovídio Pires de Campos, 225 - 50 andar - tel: 2661-6442 ramais 16, 17, 18 ou 20, FAX: 2661-6442 ramal 26 - E-mail: cappesq@henet.usp.br

Acredito ter sido suficientemente informado a respeito das informações que li ou que foram lidas para mim, descrevendo o estudo "ESTUDO COMPARATIVO ENTRE RESPOSTAS AUDITIVAS DE ESTADO ESTÁVEL E AVALIAÇÃO SUBJETIVA NA INFÂNCIA”

Eu discuti com o Dr. Roberto Miquelino de Oliveira Beck sobre a minha decisão em participar nesse estudo. Ficaram claros para mim quais são os propósitos do estudo, os procedimentos a serem realizados, seus desconfortos e riscos, as garantias de confidencialidade e de esclarecimentos permanentes. Ficou claro também que a participação da criança é isenta de despesas e que tenho garantia do acesso a tratamento hospitalar quando necessário. Concordo voluntariamente que meu filho(a) participe deste estudo e poderei retirar o meu consentimento a qualquer momento, antes ou durante o mesmo, sem penalidades ou prejuízo ou perda de qualquer benefício que ele(a) possa ter adquirido, ou no meu atendimento neste Serviço.

Assinatura do paciente/representante legal

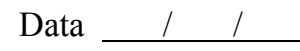

Assinatura da testemunha

Data

para casos de pacientes menores de 18 anos, analfabetos, semi-analfabetos ou portadores de deficiência auditiva ou visual.

(Somente para o responsável do projeto)

Declaro que obtive de forma apropriada e voluntária o Consentimento Livre e Esclarecido deste paciente ou representante legal para a participação neste estudo. 
Anexo D - Anamnese crianças

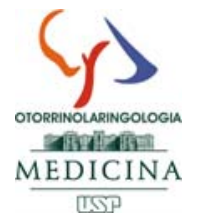

\section{HOSPITAL DAS CLÍNICAS - FMUSP \\ SETOR DE ELETROFISIOLOGIA - AVALIAÇÃO AUDITIVA NA INFÂNCIA}

IDENTIFICAÇÃO:

NOME:

DATA DE NASCIMENTO:

COR:

ENDEREÇO:

MUNICÍPIO:

ENCAMINHADO DE:

RGHC:

MÃE:

FUMANTE ( )SIM ( ) NÃO

ETILISTA ( )SIM ( ) NÃO

OUTRAS DROGAS ( )SIM ( ) NÃO

IDADE DA MÃE NO PARTO: CONSANGUINIDADE: ( )SIM ( ) NÃO

SURDEZ NA FAMÍLIA: ( )SIM ( ) ) NÃO, GRAU DE PARENTESCO:

GESTAÇÃO:

QUAL GESTA DA CRIANÇA:

DOENÇAS NA GRAVIDEZ: ( )SIM

CMV? ( )SIM ( ) NÃO

ABORTO:

MEDICAÇÕES NA GRAVIDEZ:

\section{PARTO:}

NORMAL CESÁREA FÓRCEPS

TERMO : SEMANAS

PREMATURIDADE: SEMANAS

PESO:

CHOROU LOGO QUE NASCEU: ( )SIM

INTERCORRÊNCIAS NO PARTO: ( )SIM

UTI ( )SIM ( ) NÃO

OTOTÓXICOS: ( )SIM ( ) NÃO

MALFORMAÇÕES: ( )SIM ( ) NÃO

( ) NÃO QUAL:

TELEFONES:

CEP:

DATA DO EXAME:

OUTRAS DOENÇAS:

( ) NÃO

( ) NÃO

TEMPO DE UTI:

QUAIS? DIAS QUAIS?

PÓS-NATAL

ICTERÍCIA: ( )SIM ( ) NÃO FOTOTERAPIA EXSANGUINEOTRANSFUSÃO MENINGITE: ( )SIM ( ) NÃO IDADE:__ (MESES) BACTERIANA VIRAL

DESENVOLVIMENTO

- NEUROLÓGICO: NORMAL ALTERADO

- MOTOR: NORMAL ATRASADO

- LINGUAGEM: NORMAL ATRASADO

OTITES:

ALERGIAS MEDICAMENTOS: ( )NÃO ( ) SIM Qual?

ALERGIAS RESPIRATÓRIAS: ( )NÃO ( ) SIM Qual?

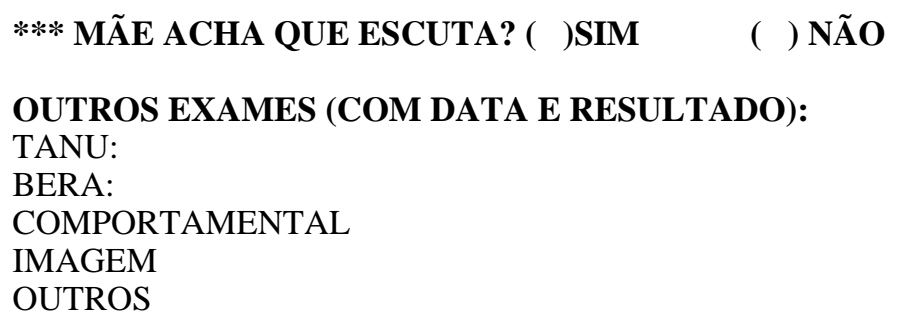




\section{Anexo E - Banco de dados com os resultados da avaliação comportamental}

\begin{tabular}{|c|c|c|c|c|c|c|c|c|}
\hline & \multicolumn{4}{|c|}{ orelha direita } & \multicolumn{4}{|c|}{ orelha esquerda } \\
\hline & $500 \mathrm{~Hz}$ & $1000 \mathrm{~Hz}$ & $2000 \mathrm{~Hz}$ & $4000 \mathrm{~Hz}$ & $500 \mathrm{~Hz}$ & $1000 \mathrm{~Hz}$ & $2000 \mathrm{~Hz}$ & $4000 \mathrm{~Hz}$ \\
\hline 1 & - & - & - & - & 95 & 95 & - & - \\
\hline 2 & 110 & 105 & 115 & - & - & - & - & - \\
\hline 3 & 95 & 100 & 100 & - & 95 & - & - & - \\
\hline 4 & - & - & - & - & 85 & - & - & - \\
\hline 5 & - & - & - & - & - & - & - & - \\
\hline 6 & - & - & - & - & - & - & - & - \\
\hline 7 & 90 & - & - & - & 90 & 100 & - & - \\
\hline 8 & 75 & 85 & 115 & - & 85 & 80 & 90 & - \\
\hline 9 & - & - & - & - & - & - & - & - \\
\hline 10 & 100 & 105 & 115 & - & 90 & 110 & 115 & 110 \\
\hline 11 & 95 & - & - & - & 95 & - & - & - \\
\hline 12 & - & - & - & - & - & - & - & - \\
\hline 13 & - & - & - & - & - & - & - & - \\
\hline 14 & - & - & - & - & - & - & - & - \\
\hline 15 & - & - & - & - & - & - & - & - \\
\hline 16 & 90 & 90 & - & - & 90 & 90 & - & - \\
\hline 17 & - & - & 100 & - & 80 & 100 & - & - \\
\hline 18 & - & 110 & - & - & 110 & 120 & - & 115 \\
\hline 19 & - & - & - & - & - & - & - & - \\
\hline 20 & 85 & 95 & 115 & - & 90 & 100 & 120 & - \\
\hline 21 & - & - & - & - & - & - & - & - \\
\hline 22 & - & - & 110 & - & - & - & - & - \\
\hline 23 & - & - & - & - & 80 & 90 & - & - \\
\hline 24 & 90 & - & - & - & - & - & - & - \\
\hline 25 & - & - & - & - & - & - & - & - \\
\hline 26 & - & - & - & - & - & - & - & - \\
\hline 27 & - & - & - & - & - & - & - & - \\
\hline 28 & - & - & - & - & - & - & - & - \\
\hline 29 & - & - & - & - & - & - & - & - \\
\hline 30 & - & - & - & - & - & - & - & - \\
\hline 31 & 90 & 100 & 100 & 90 & 95 & 95 & 85 & 70 \\
\hline
\end{tabular}


Anexo E - Banco de dados com os resultados da avaliação comportamental (conclusão)

\begin{tabular}{|c|c|c|c|c|c|c|c|c|}
\hline & \multicolumn{4}{|c|}{ orelha direita } & \multicolumn{4}{|c|}{ orelha esquerda } \\
\hline & $500 \mathrm{~Hz}$ & $1000 \mathrm{~Hz}$ & $2000 \mathrm{~Hz}$ & $4000 \mathrm{~Hz}$ & $500 \mathrm{~Hz}$ & $1000 \mathrm{~Hz}$ & $2000 \mathrm{~Hz}$ & $4000 \mathrm{~Hz}$ \\
\hline 32 & - & - & - & - & - & - & - & - \\
\hline 33 & 110 & 120 & - & - & 110 & 120 & - & - \\
\hline 34 & 75 & 80 & 65 & 80 & 50 & 50 & 50 & 65 \\
\hline 35 & 110 & - & - & - & 100 & 105 & 105 & 100 \\
\hline 36 & 95 & 100 & 100 & - & 100 & - & 95 & - \\
\hline 37 & 85 & 90 & 85 & 85 & 75 & 80 & 85 & 80 \\
\hline 38 & 100 & 110 & 115 & - & 105 & - & - & - \\
\hline 39 & - & - & - & - & - & - & - & - \\
\hline 40 & - & - & - & - & - & - & - & - \\
\hline 41 & 95 & 110 & - & - & 95 & 110 & - & - \\
\hline 42 & - & - & - & - & - & - & - & - \\
\hline 43 & 80 & 95 & - & - & 80 & 95 & - & - \\
\hline 44 & 95 & 95 & - & - & 95 & 95 & - & - \\
\hline 45 & 90 & 95 & - & - & - & - & - & - \\
\hline 46 & 100 & 90 & - & - & 90 & 80 & 95 & 110 \\
\hline 47 & 90 & - & - & - & 90 & - & - & - \\
\hline 48 & - & - & - & 80 & - & - & - & 80 \\
\hline 49 & 100 & 100 & 100 & - & 95 & 100 & 110 & - \\
\hline 50 & 70 & 60 & 110 & 110 & 65 & 90 & 110 & 110 \\
\hline 51 & 100 & 100 & 100 & 100 & 95 & 100 & 100 & 100 \\
\hline 52 & 100 & 110 & 115 & - & 95 & 105 & 115 & - \\
\hline 53 & 105 & 100 & 100 & 110 & 100 & 95 & 100 & 100 \\
\hline 54 & 95 & 105 & 105 & 120 & 95 & 105 & 120 & 120 \\
\hline 55 & - & - & - & - & - & - & - & - \\
\hline 56 & 70 & 90 & - & - & - & - & - & - \\
\hline 57 & 95 & 85 & 85 & - & 95 & 95 & 95 & - \\
\hline 58 & 110 & 105 & 120 & - & 110 & 110 & 110 & - \\
\hline 59 & 110 & - & - & - & 100 & 110 & - & - \\
\hline 60 & - & - & - & - & - & - & - & - \\
\hline 61 & - & - & - & - & - & - & - & - \\
\hline 62 & 80 & 75 & 80 & 90 & 75 & 85 & 90 & 90 \\
\hline 63 & - & - & - & - & 110 & - & - & - \\
\hline
\end{tabular}


Anexo F. Banco de dados com os resultados da Resposta Auditiva de Estado Estável

\begin{tabular}{|c|c|c|c|c|c|c|c|c|}
\hline \multirow{2}{*}{$\begin{array}{l}\text { RAEE } \\
\text { paciente }\end{array}$} & \multicolumn{4}{|c|}{ Orelha Direita } & \multicolumn{4}{|c|}{ Orelha esquerda } \\
\hline & $500 \mathrm{~Hz}$ & $1000 \mathrm{~Hz}$ & $2000 \mathrm{~Hz}$ & $4000 \mathrm{~Hz}$ & $500 \mathrm{~Hz}$ & $1000 \mathrm{~Hz}$ & $2000 \mathrm{~Hz}$ & $4000 \mathrm{~Hz}$ \\
\hline 1 & - & - & - & - & 100 & - & - & - \\
\hline 2 & 100 & 100 & 100 & 100 & 100 & 100 & 100 & - \\
\hline 3 & - & - & - & - & - & - & - & - \\
\hline 4 & - & - & - & - & - & - & - & - \\
\hline 5 & - & - & - & - & 100 & - & - & - \\
\hline 6 & - & - & - & - & - & - & - & - \\
\hline 7 & - & - & - & - & - & - & - & - \\
\hline 8 & - & - & - & - & - & - & - & - \\
\hline 9 & - & - & - & - & - & - & - & - \\
\hline 10 & - & - & - & - & - & - & - & - \\
\hline 11 & - & - & - & - & - & - & - & - \\
\hline 12 & - & - & - & - & - & - & - & - \\
\hline 13 & - & - & - & - & 100 & - & - & - \\
\hline 14 & - & - & - & - & - & - & - & - \\
\hline 15 & - & - & - & - & - & - & - & - \\
\hline 16 & - & - & - & - & - & - & - & - \\
\hline 17 & 80 & 100 & - & - & - & - & - & - \\
\hline 18 & - & - & - & - & - & - & - & - \\
\hline 19 & - & - & - & - & - & - & - & - \\
\hline 20 & - & - & - & - & - & - & - & - \\
\hline 21 & - & - & - & - & - & 100 & - & - \\
\hline 22 & 100 & - & - & - & 100 & - & - & - \\
\hline 23 & - & - & - & - & - & 100 & - & - \\
\hline 24 & - & - & - & - & - & - & - & - \\
\hline 25 & - & - & - & - & - & - & - & - \\
\hline 26 & - & - & - & - & - & - & - & - \\
\hline 27 & - & - & - & - & - & - & - & - \\
\hline 28 & - & - & - & - & - & - & - & - \\
\hline 29 & - & - & - & - & - & - & - & - \\
\hline 30 & - & - & - & - & - & - & - & - \\
\hline 31 & - & - & - & - & 100 & 100 & - & - \\
\hline
\end{tabular}


Anexo F. Banco de dados com os resultados da Resposta Auditiva de Estado Estável (conclusão)

\begin{tabular}{|c|c|c|c|c|c|c|c|c|}
\hline \multirow{2}{*}{$\begin{array}{c}\text { RAEE } \\
\text { paciente }\end{array}$} & \multicolumn{4}{|c|}{ Orelha Direita } & \multicolumn{4}{|c|}{ Orelha esquerda } \\
\hline & $500 \mathrm{~Hz}$ & $1000 \mathrm{~Hz}$ & $2000 \mathrm{~Hz}$ & $4000 \mathrm{~Hz}$ & $500 \mathrm{~Hz}$ & $1000 \mathrm{~Hz}$ & $2000 \mathrm{~Hz}$ & $4000 \mathrm{~Hz}$ \\
\hline 32 & - & - & - & - & 90 & - & - & - \\
\hline 33 & - & - & - & - & - & - & - & - \\
\hline 34 & 100 & - & - & - & - & - & - & - \\
\hline 35 & - & - & - & - & - & - & - & - \\
\hline 36 & 100 & 100 & 100 & 100 & - & - & - & - \\
\hline 37 & 100 & 90 & 100 & - & 100 & 100 & 90 & - \\
\hline 38 & - & - & - & - & - & - & - & - \\
\hline 39 & 110 & 110 & - & 110 & 110 & 110 & - & 110 \\
\hline 40 & - & - & - & - & - & - & - & - \\
\hline 41 & - & - & - & - & - & - & - & - \\
\hline 42 & - & - & - & - & - & - & - & - \\
\hline 43 & - & - & - & - & - & - & - & - \\
\hline 44 & - & - & - & - & - & - & - & - \\
\hline 45 & 110 & 110 & - & - & 110 & 110 & - & - \\
\hline 46 & - & - & - & - & - & - & - & - \\
\hline 47 & 110 & 110 & 110 & 110 & 110 & - & 110 & - \\
\hline 48 & - & - & - & - & - & - & - & - \\
\hline 49 & - & - & - & - & - & - & - & - \\
\hline 50 & - & - & - & - & - & - & 110 & - \\
\hline 51 & 100 & 100 & - & - & 100 & 90 & 90 & 70 \\
\hline 52 & - & - & - & - & - & - & - & - \\
\hline 53 & - & - & - & - & - & - & - & - \\
\hline 54 & - & - & - & - & - & - & - & - \\
\hline 55 & - & - & - & - & - & - & - & - \\
\hline 56 & - & - & - & - & - & - & - & - \\
\hline 57 & - & - & - & - & - & - & - & - \\
\hline 58 & - & - & - & - & - & - & - & - \\
\hline 59 & - & - & - & - & - & - & - & - \\
\hline 60 & - & - & - & - & - & - & - & - \\
\hline 61 & - & - & - & - & - & - & - & - \\
\hline 62 & - & - & - & - & - & - & - & - \\
\hline 63 & - & - & - & - & - & - & - & - \\
\hline
\end{tabular}


REFERÊNCIAS 


\section{REFERÊNCIAS}

1 Nikolopoulos TP, O'Donoghue GM, Archbold S. Age at implantation: its importance in pediatric cochlear implantation. Laryngoscope. 1999;109(4):595-9.

2. Kirk KI, Miyamoto RT, Lento CL, Ying E, O'Neill T, Fears B. Effects of age at implantation in young children. Ann Otol Rhinol Laryngol Suppl. 2002;189:69-73.

3. Zwolan TA, Zimmerman-Phillips S, Ashbaugh CJ, Hieber SJ, Kileny PR, Telian SA. Cochlear implantation of children with minimal open-set speech recognition skills. Ear Hear. 1997;18(3):240-51.

4. Eisenberg LS, Martinez AS, Sennaroglu G, Osberger MJ. Establishing new criteria in selecting children for a cochlear implant: performance of "platinum" hearing aid users. Ann Otol Rhinol Laryngol Suppl. 2000;185:30-3.

5. Battmer RD, Gupta SP, Allum-Mecklenburg DJ, Lenarz T. Factors influencing cochlear implant perceptual performance in 132 adults. Ann Otol Rhinol Laryngol Suppl. 1995;166:185-7.

6. Summerfield AQ, Marshall DH. Preoperative predictors of outcomes from cochlear implantation in adults: performance and quality of life. Ann Otol Rhinol Laryngol Suppl. 1995;166:105-8.

7. NIH. NIH consensus conference. Cochlear implants in adults and children. JAMA. 1995;274(24):1955-61.

8. ABORLCCF S, SBF, ABA e SBP. Critérios de Indicação para Implante Coclear http://www.aborlccf.org.br: ABORL-CCF; 2011 [cited 2013 november2013]. Available from: http://www.aborlccf.org.br/imageBank/DIRETRIZES PUBLICACAO SITE.pdf. 
9. Bento R, Bittencourt A, Voegels R. Implante coclear. Seminários em Otorrinolaringologia. 1. São Paulo: H Maxima; 2013. p. 9.

10. Azevedo M. Programa de prevenção e identificação precoce dos distúrbios de audição. In: Schochat E, editor. Processamento auditivo. São Paulo: Editora Lovise; 1996. p. 75-96.

11. Azevedo M. Avaliação audiológica no primeiro ano de vida. In: Lopes Filho OC, editor. Tratado de fonoaudiologia. São Paulo: Editora Roca; 1997. p. 241-63.

12. Williamson T. Neonatal hearing screening and assessment behavioural observation audiometry. A recommended test protocol http://www.nhsp.info/ workbook.shtml: Newborn Hearing Screening Programme Home Page; 2002 [cited 2013].

13. Firszt JB, Gaggl W, Runge-Samuelson CL, Burg LS, Wackym PA. Auditory sensitivity in children using the auditory steady-state response. Arch Otolaryngol Head Neck Surg. 2004;130(5):536-40.

14. Swanepoel D, Hugo R. Estimations of auditory sensitivity for young cochlear implant candidates using the ASSR: preliminary results. Int J Audiol. 2004; 43(7):377-82.

15. Rance G, Dowell RC, Rickards FW, Beer DE, Clark GM. Steady-state evoked potential and behavioral hearing thresholds in a group of children with absent click-evoked auditory brain stem response. Ear Hear. 1998;19(1):48-61.

16. Lins OG, Picton TW, Boucher BL, Durieux-Smith A, Champagne SC, Moran LM, Perez-Abalo MC, Martin V, Savio G. Frequency-specific audiometry using steady-state responses. Ear Hear. 1996;17(2):81-96. 
17. SUS. Critérios de indicação de implante coclear Brasil: Sistema Nacional de Auditoria; 1999 [cited 2014 January, 2014]. Available from: http://sna.saude.gov.br/ legisla/legisla/alta_impl_coc/.

18. Kiefer J, Gstoettner W, Baumgartner W, Pok SM, Tillein J, Ye Q, von Ilberg C. Conservation of low-frequency hearing in cochlear implantation. Acta Otolaryngol. 2004;124(3):272-80.

19. James C, Albegger K, Battmer R, Burdo S, Deggouj N, Deguine O, Dillier N, Gersdorff M, Laszig R, Lenarz T, Rodriguez MM, Mondain M, Offeciers E, Macías AR, Ramsden R, Sterkers O, Von Wallenberg E, Weber B, Fraysse B. Preservation of residual hearing with cochlear implantation: how and why. Acta Otolaryngol. 2005;125(5):481-91.

20. Ramos H. Avaliação da audição residual em candidatos a implante coclear atraves da resposta auditiva de estado estável. São Paulo: Universidade de São Paulo; 2013.

21. Dowell RC, Hollow R, Winton E. Outcomes for cochlear implant users with significant residual hearing: implications for selection criteria in children. Arch Otolaryngol Head Neck Surg. 2004;130(5):575-81.

22. Cullen RD, Higgins C, Buss E, Clark M, Pillsbury HC, 3rd, Buchman CA. Cochlear implantation in patients with substantial residual hearing. Laryngoscope. 2004;114(12):2218-23.

23. Santos A, Felix F, Martins G, Pinna M, Bento R, Monteiro T, et al. Perda auditiva neurossensorial: tratamento http://www.projetodiretrizes.org.br/diretrizes11/ perda_auditiva_neurossensorial_tratamento.pdf: Associação Médica Brasileira; 2011 [cited 2013 August, 2013]. 
24. Skinner MW, Clark GM, Whitford LA, Seligman PM, Staller SJ, Shipp DB, et al. Evaluation of a new spectral peak coding strategy for the Nucleus 22 Channel Cochlear Implant System. Am J Otol. 1994;15 Suppl 2:15-27.

25. Whitford LA, Seligman PM, Everingham CE, Antognelli T, Skok MC, Hollow RD, et al. Evaluation of the Nucleus Spectra 22 processor and new speech processing strategy (SPEAK) in postlinguistically deafened adults. Acta Otolaryngol. 1995;115(5):629-37.

26. Flynn MC, Dowell RC, Clark GM. Aided speech recognition abilities of adults with a severe or severe-to-profound hearing loss. J Speech Lang Hear Res. 1998;41(2):285-99.

27. Yoshinaga-Itano C, Sedey AL, Coulter DK, Mehl AL. Language of early- and later-identified children with hearing loss. Pediatrics. 1998;102(5):1161-71.

28. Van den Borne S, Snik AF, Hoekstra CC,Vermeulen AM, Van den Broek P, Brokx JP. Assessment of basal sound identification skills and communication abilities in profoundly deaf children fitted with hearing aids or a cochlear implant. Clin Otolaryngol Allied Sci. 1998;23(5):455-61.

29. Tomblin JB, Spencer L, Flock S, Tyler R, Gantz B. A comparison of language achievement in children with cochlear implants and children using hearing aids. J Speech Lang Hear Res. 1999;42(2):497-509.

30. Kiefer J, von Ilberg C, Reimer B, Knecht R, Gall V, Diller G, Stürzebecher E, Pfennigdorff T, Spelsberg A. Results of cochlear implantation in patients with severe to profound hearing loss--implications for patient selection. Audiology. 1998;37(6):382-95.

31. Gantz BJ, Rubinstein JT, Tyler RS, Teagle HF, Cohen NL, Waltzman SB, Miyamoto RT, Kirk KI. Long-term results of cochlear implants in children with residual hearing. Ann Otol Rhinol Laryngol Suppl. 2000;185:33-6. 
32. Dolan-Ash S, Hodges AV, Butts SL, Balkany TJ. Borderline pediatric cochlear implant candidates: preoperative and postoperative results. Ann Otol Rhinol Laryngol Suppl. 2000;185:36-8.

33. Mondain M, Sillon M, Vieu A, Levi A, Reuillard-Artieres F, Deguine O, Fraysse B, Cochard N, Truy E, Uziel A. Cochlear implantation in prelingually deafened children with residual hearing. Int J Pediatr Otorhinolaryngol. 2002;63(2):91-7.

34 Fraysse B, Dillier N, Klenzner T, Laszig R, Manrique M, Morera Perez C, Morgon AH, Müller-Delle J, Ramos Macias A. Cochlear implants for adults obtaining marginal benefit from acoustic amplification: a European study. Am J Otol. 1998;19(5):591-7.

35 Shiomi Y, Naito Y, Honjo I, Fujiki N, Kaneko K, Takahashi H, Yamashita M, Kawano M. Cochlear implant in patients with residual hearing. Auris Nasus Larynx. 1999;26(4):369-74.

36 Soda-Merhy A, Gonzalez-Valenzuela L, Tirado-Gutierrez C. Residual hearing preservation after cochlear implantation: comparison between straight and perimodiolar implants. Otolaryngol Head Neck Surg. 2008;139(3):399-404.

37 Francis HW, Yeagle JD, Brightwell T, Venick H. Central effects of residual hearing: implications for choice of ear for cochlear implantation. Laryngoscope. 2004;114(10):1747-52.

38 Baudonck N, Dhooge I, Van Lierde K. Intelligibility of hearing impaired children as judged by their parents: A comparison between children using cochlear implants and children using hearing aids. Int J Pediatr Otorhinolaryngol. 2010; 74(11):1310-5.

39. Russell JL, Pine HS, Young DL. Pediatric cochlear implantation: expanding applications and outcomes. Pediatr Clin North Am. 2013;60(4):841-63. 
40. FDA. Cochlear Implants. Disponível em: http://www.fda.gov/ MedicalDevices/ProductsandMedicalProcedures/ImplantsandProsthetics/CochlearIm plants/default.htm2009 [cited 2013 november, 2013].

41. Leigh J, Dettman S, Dowell R, Sarant J. Evidence-based approach for making cochlear implant recommendations for infants with residual hearing. Ear Hear. 2011;32(3):313-22.

42. Govaerts PJ, De Beukelaer C, Daemers K, De Ceulaer G, Yperman M, Somers T, Schatteman I, Offeciers FE. Outcome of cochlear implantation at different ages from 0 to 6 years. Otol Neurotol. 2002;23(6):885-90.

43. Tajudeen BA, Waltzman SB, Jethanamest D, Svirsky MA. Speech perception in congenitally deaf children receiving cochlear implants in the first year of life. Otol Neurotol. 2010;31(8):1254-60.

44. Colletti L, Mandala M, Colletti V. Cochlear implants in children younger than 6 months. Otolaryngol Head Neck Surg. 2012;147(1):139-46.

45. Sharma A, Campbell J. A sensitive period for cochlear implantation in deaf children. J Matern Fetal Neonatal Med. 2011;24 Suppl 1:151-3.

46. Tobey EA, Geers AE, Sundarrajan M, Shin S. Factors influencing speech production in elementary and high school-aged cochlear implant users. Ear Hear. 2011;32(1 Suppl):27S-38S.

47. Robbins AM, Renshaw JJ, Berry SW. Evaluating meaningful auditory integration in profoundly hearing-impaired children. Am J Otol. 1991;12 Suppl:14450 .

48. Uziel AS, Sillon M, Vieu A, Artieres F, Piron JP, Daures JP, Mondain M. Ten-year follow-up of a consecutive series of children with multichannel cochlear implants. Otol Neurotol. 2007;28(5):615-28. 
49. Ramsden JD, Gordon K, Aschendorff A, Borucki L, Bunne M, Burdo S, Garabedian N, Grolman W, Irving R, Lesinski-Schiedat A, Loundon N, Manrique M, Martin J, Raine C, Wouters J, Papsin BC. European Bilateral Pediatric Cochlear Implant Forum consensus statement. Otol Neurotol. 2012;33(4):561-5.

50. Basura GJ, Eapen R, Buchman CA. Bilateral cochlear implantation: current concepts, indications, and results. Laryngoscope. 2009;119(12):2395-401.

51. Galambos R, Makeig S, Talmachoff PJ. A 40-Hz auditory potential recorded from the human scalp. Proc Natl Acad Sci U S A. 1981;78(4):2643-7.

52. Jerger J, Chmiel R, Frost JD, Jr., Coker N. Effect of sleep on the auditory steady state evoked potential. Ear Hear. 1986;7(4):240-5.

53. Cohen LT, Rickards FW, Clark GM. A comparison of steady-state evoked potentials to modulated tones in awake and sleeping humans. J Acoust Soc Am. 1991;90(5):2467-79.

54. Kiren T, Aoyagi M, Furuse H, Koike Y. An experimental study on the generator of amplitude-modulation following response. Acta Otolaryngol Suppl. 1994;511:28-33.

55. Herdman AT, Picton TW, Stapells DR. Place specificity of multiple auditory steady-state responses. J Acoust Soc Am. 2002;112(4):1569-82.

56. Stapells DR, Makeig S, Galambos R. Auditory steady-state responses: threshold prediction using phase coherence. Electroencephalogr Clin Neurophysiol. 1987;67(3):260-70.

57. Rickards FW, Tan LE, Cohen LT, Wilson OJ, Drew JH, Clark GM. Auditory steady-state evoked potential in newborns. Br J Audiol. 1994;28(6):327-37. 
58. Rance G, Rickards FW, Cohen LT, De Vidi S, Clark GM. The automated prediction of hearing thresholds in sleeping subjects using auditory steady-state evoked potentials. Ear Hear. 1995;16(5):499-507.

59. Lins OG, Picton TW. Auditory steady-state responses to multiple simultaneous stimuli. Electroencephalogr Clin Neurophysiol. 1995;96(5):420-32.

60. Dobie RA, Wilson MJ. A comparison of $t$ test, $F$ test, and coherence methods of detecting steady-state auditory-evoked potentials, distortion-product otoacoustic emissions, or other sinusoids. J Acoust Soc Am. 1996;100(4 Pt 1):2236-46.

61. Dimitrijevic A, John MS, Van Roon P, Purcell DW, Adamonis J, Ostroff J, Nedzelski JM, Picton TW. Estimating the audiogram using multiple auditory steadystate responses. J Am Acad Audiol. 2002;13(4):205-24.

62. Picton TW, Dimitrijevic A, Perez-Abalo MC, Van Roon P. Estimating audiometric thresholds using auditory steady-state responses. J Am Acad Audiol. 2005;16(3):140-56.

63. Vander Werff KR, Brown CJ. Effect of audiometric configuration on threshold and suprathreshold auditory steady-state responses. Ear Hear. 2005;26(3): 310-26.

64. Attias J, Buller N, Rubel Y, Raveh E. Multiple auditory steady-state responses in children and adults with normal hearing, sensorineural hearing loss, or auditory neuropathy. Ann Otol Rhinol Laryngol. 2006;115(4):268-76.

65. Canale A, Lacilla M, Cavalot AL, Albera R. Auditory steady-state responses and clinical applications. Eur Arch Otorhinolaryngol. 2006;263(6):499-503.

66. Ahn JH, Lee HS, Kim YJ, Yoon TH, Chung JW. Comparing pure-tone audiometry and auditory steady state response for the measurement of hearing loss. Otolaryngol Head Neck Surg. 2007;136(6):966-71. 
67. D'Haenens W, Dhooge I, Maes L, Bockstael A, Keppler H, Philips B, Swinnen F, Vinck BM. The clinical value of the multiple-frequency $80-\mathrm{Hz}$ auditory steady-state response in adults with normal hearing and hearing loss. Arch Otolaryngol Head Neck Surg. 2009;135(5):496-506.

68. Ozdek A, Karacay M, Saylam G, Tatar E, Aygener N, Korkmaz MH. Comparison of pure tone audiometry and auditory steady-state responses in subjects with normal hearing and hearing loss. Eur Arch Otorhinolaryngol. 2010;267(1):43-9.

69. Rance G, Briggs RJ. Assessment of hearing in infants with moderate to profound impairment: the Melbourne experience with auditory steady-state evoked potential testing. Ann Otol Rhinol Laryngol Suppl. 2002;189:22-8.

70. Aoyagi M, Suzuki Y, Yokota M, Furuse H, Watanabe T, Ito T. Reliability of $80-\mathrm{Hz}$ amplitude-modulation-following response detected by phase coherence. Audiol Neurootol. 1999;4(1):28-37.

71. Herdman AT, Stapells DK. Auditory steady-state response thresholds of adults with sensorineural hearing impairments. Int J Audiol. 2003;42(5):237-48.

72. D'Haenens W, Vinck BM, De Vel E, Maes L, Bockstael A, Keppler H, Philips B, Swinnen F, Dhooge I. Auditory steady-state responses in normal hearing adults: a test-retest reliability study. Int J Audiol. 2008;47(8):489-98.

73. Lin YH, Ho HC, Wu HP. Comparison of auditory steady-state responses and auditory brainstem responses in audiometric assessment of adults with sensorineural hearing loss. Auris Nasus Larynx. 2009;36(2):140-5.

74. Luts H, Desloovere C, Kumar A, Vandermeersch E, Wouters J. Objective assessment of frequency-specific hearing thresholds in babies. Int $\mathrm{J}$ Pediatr Otorhinolaryngol. 2004;68(7):915-26. 
75. Vander Werff KR, Brown CJ, Gienapp BA, Schmidt Clay KM. Comparison of auditory steady-state response and auditory brainstem response thresholds in children. J Am Acad Audiol. 2002;13(5):227-35; quiz 83-4.

76. Tlumak AI, Rubinstein E, Durrant JD. Meta-analysis of variables that affect accuracy of threshold estimation via measurement of the auditory steady-state response (ASSR). Int J Audiol. 2007;46(11):692-710.

77. Roberson JB, Jr., O'Rourke C, Stidham KR. Auditory steady-state response testing in children: evaluation of a new technology. Otolaryngol Head Neck Surg. 2003;129(1):107-13.

78. Swanepoel D, Hugo R, Roode R. Auditory steady-state responses for children with severe to profound hearing loss. Arch Otolaryngol Head Neck Surg. 2004; 130(5):531-5.

79. Lee HS, Kim HN, Jung MH, Choi JY. Prediction of hearing sensitivity with multiple auditory steady-state responses (MASTER) for severe to profound hearing loss. Cochlear Implants Int. 2004;5 Suppl 1:199-200.

80. Beck RMO RH, Grasel SS, de Almeida ER, Brito-Neto R. Auditory SteadyState Responses (ASSR) in young cochlear implant candidates. Int J Pediatr Otorhinolaryngol. 2011;75(Suppl 1):97.

81. Beck RMO, Tsuji RK, Ramos HF, Brito-Neto RV, Almeida ER, Grasel SS, Rossi AC. Hearing evaluation for pediatric cochlear implant with ASSR. Otolaryngol Head Neck Surg. 2012;147 (suppl 2):101.

82. Rance G, Rickards F. Prediction of hearing threshold in infants using auditory steady-state evoked potentials. J Am Acad Audiol. 2002;13(5):236-45.

83. Picton TW, John MS. Avoiding electromagnetic artifacts when recording auditory steady-state responses. J Am Acad Audiol. 2004;15(8):541-54. 
84. Small SA, Stapells DR. Artifactual responses when recording auditory steady-state responses. Ear Hear. 2004;25(6):611-23.

85. Gorga MP, Neely ST, Hoover BM, Dierking DM, Beauchaine KL, Manning C. Determining the upper limits of stimulation for auditory steady-state response measurements. Ear Hear. 2004;25(3):302-7.

86. Welgampola MS, Colebatch JG. Characteristics of tone burst-evoked myogenic potentials in the sternocleidomastoid muscles. Otol Neurotol. 2001; 22(6):796-802.

87. Colebatch JG, Rothwell JC. Motor unit excitability changes mediating vestibulocollic reflexes in the sternocleidomastoid muscle. Clin Neurophysiol. 2004;115(11):2567-73.

88. Ramos HF, Grasel SS, Beck RM, Takahashi-Ramos MT, Ramos BF, de Almeida ER, Bento RF, de Brito Neto R. Evaluation of residual hearing in cochlear implants candidates using auditory steady-state response. Acta Otolaryngol. 2015; 135(3):246-53.

89. Jerger JF, Hayes D. The cross-check principle in pediatric audiometry. Arch Otolaryngol. 1976;102(10):614-20.

90. Liden G, Kankkunen A. Visual reinforcement audiometry. Arch Otolaryngol. 1969;89(6):865-72.

91. Widen JE, O'Grady GM. Using visual reinforcement audiometry in the assessment of hearing in infants. Hear J. 2002;55(1):28-36.

92. Matkin ND. The audiologic examination of young children at risk. Ear Nose Throat J. 1979;58(7):297-302. 
93. Moore JM, Wilson WR, Thompson G. Visual reinforcement of head-turn responses in infants under 12 months of age. J Speech Hear Disord. 1977;42(3):32834.

94. Gravel JS, Traquina DN. Experience with the audiologic assessment of infants and toddlers. Int J Pediatr Otorhinolaryngol. 1992;23(1):59-71.

95. Talbott CB. A longitudinal study comparing responses of hearing-impaired infants to pure tones using visual reinforcement and play audiometry. Ear Hear. 1987;8(3):175-9.

96. Lopes Filho O. Tratado de Otorrinolaringologia. São Paulo: Roca; 1994.

97. Russo I, Santos T. Audiologia infantil. São Paulo: Cortez; 1994.

98. Nielsen SE, Olsen SO. Validation of play-conditioned audiometry in a clinical setting. Scand Audiol. 1997;26(3):187-91.

99. Widen JE, Folsom RC, Cone-Wesson B, Carty L, Dunnell JJ, Koebsell K, Levi A, Mancl L, Ohlrich B, Trouba S, Gorga MP, Sininger YS, Vohr BR, Norton SJ. Identification of neonatal hearing impairment: hearing status at 8 to 12 months corrected age using a visual reinforcement audiometry protocol. Ear Hear. 2000;21(5):471-87.

100. Day J, Bamford J, Parry G, Shepherd M, Quigley A. Evidence on the efficacy of insert earphone and sound field VRA with young infants. Br J Audiol. 2000; 34(6):329-34.

101. Parry G, Hacking C, Bamford J, Day J. Minimal response levels for visual reinforcement audiometry in infants. Int J Audiol. 2003;42(7):413-7. 
102. Widen JE, Johnson JL, White KR, Gravel JS, Vohr BR, James M, Kennalley T, Maxon AB, Spivak L, Sullivan-Mahoney M, Weirather Y, Meyer S. A multisite study to examine the efficacy of the otoacoustic emission/automated auditory brainstem response newborn hearing screening protocol: results of visual reinforcement audiometry. Am J Audiol. 2005;14(2):S200-16.

103. Oda AK, Bernardi APA, Azevedo MF. Comparação dos limiares auditivos tonais determinados por tom puro e por tom modulado. R Cefac. 2003;5(2):8.

104. Kandogan T, Dalgic A. Reliability of Auditory Steady-State Response (ASSR): Comparing Thresholds of Auditory Steady-State Response (ASSR) with Auditory Brainstem Response (ABR) in children with severe hearing loss. Indian $\mathbf{J}$ Otolaryngol Head Neck Surg. 2013;65(Suppl 3):604-7.

105. Wilding TS, McKay CM, Baker RJ, Kluk K. Auditory steady state responses in normal-hearing and hearing-impaired adults: an analysis of between-session amplitude and latency repeatability, test time, and F ratio detection paradigms. Ear Hear. 2012;33(2):267-78.

106. Van Maanen A, Stapells DR. Multiple-ASSR thresholds in infants and young children with hearing loss. J Am Acad Audiol. 2010;21(8):535-45.

107. Muhler R, Mentzel K, Verhey J. Fast hearing-threshold estimation using multiple auditory steady-state responses with narrow-band chirps and adaptive stimulus patterns. ScientificWorldJournal. 2012;2012:192178.

108. Tlumak AI, Durrant JD, Delgado RE, Boston JR. Steady-state analysis of auditory evoked potentials over a wide range of stimulus repetition rates: profile in children vs. adults. Int J Audiol. 2012;51(6):480-90.

109. Muhler R, Rahne T, Mentzel K, Verhey JL. 40-Hz multiple auditory steadystate responses to narrow-band chirps in sedated and anaesthetized infants. Int $\mathbf{J}$ Pediatr Otorhinolaryngol. 2014;78(5):762-8. 